NBER WORKING PAPER SERIES

\title{
EXPORTING UNCERTAINTY: \\ THE IMPACT OF BREXIT ON CORPORATE AMERICA
}

\author{
Murillo Campello \\ Gustavo S. Cortes \\ Fabricio d'Almeida \\ Gaurav Kankanhalli \\ Working Paper 26714 \\ http://www.nber.org/papers/w26714 \\ NATIONAL BUREAU OF ECONOMIC RESEARCH \\ 1050 Massachusetts Avenue \\ Cambridge, MA 02138 \\ January 2020, Revised May 2021
}

We are grateful to Warren Bailey, Craig Brown, Charles Calomiris, Danilo Cascaldi-Garcia, Steven Davis, Price Fishback, Janet Gao, Jesús Gorrín, John Graham, Darien Huang, Tim Johnson, Hyunseob Kim, Mauricio Larrain, Angie Low, Diogo Palhares, Minchul Shin, Felipe Silva, Allan Timmermann, and seminar participants at the Bank of Portugal, Bristol Workshop on Banking, Cambridge University, George Washington University, Hoover Institution, KU Leuven, LUBRAFIN Conference, Manchester Business School, National Bank of Belgium, Penn State, SFS Cavalcade, Syracuse University, University of Connecticut, University of Georgia, University of Illinois, University of Kentucky, Warwick Business School, and Washington University St. Louis for many useful comments. The views expressed herein are those of the authors and do not necessarily reflect the views of the National Bureau of Economic Research.

NBER working papers are circulated for discussion and comment purposes. They have not been peer-reviewed or been subject to the review by the NBER Board of Directors that accompanies official NBER publications.

(C) 2020 by Murillo Campello, Gustavo S. Cortes, Fabricio d'Almeida, and Gaurav Kankanhalli. All rights reserved. Short sections of text, not to exceed two paragraphs, may be quoted without explicit permission provided that full credit, including $\odot$ notice, is given to the source. 
Exporting Uncertainty: The Impact of Brexit on Corporate America

Murillo Campello, Gustavo S. Cortes, Fabricio d'Almeida, and Gaurav Kankanhalli

NBER Working Paper No. 26714

January 2020, Revised May 2021

JEL No. F23,G15,G31

\begin{abstract}
$\underline{\text { ABSTRACT }}$
We show that the 2016 Brexit Referendum had multi-faceted consequences for corporate America, shaping employment, investment, divestitures, R\&D, and savings. The unexpected vote outcome led US firms to cut jobs and investment within US borders. Using establishment-level data, we document that these effects were modulated by the reversibility of capital and labor. American-based job destruction was particularly pronounced in industries with less skilled and more unionized workers. UK-exposed firms with less redeployable capital and high inputoffshoring dependence cut investment the most. Data on the near-universe of US establishments also point to measurable, negative effects on establishment turnover (openings and closings). Our results demonstrate how foreign-born political uncertainty is transmitted across international borders, shaping domestic capital formation and labor allocation.
\end{abstract}

Murillo Campello

Johnson Graduate School of Management

Cornell University

114 East Avenue

369 Sage Hall

Ithaca, NY 14853-6201

and NBER

campello@cornell.edu

Gustavo S. Cortes

Warrington College of Business

University of Florida

306 Stuzin Hall, PO Box 117168

Gainesville, FL 32611

gustavo.cortes@warrington.ufl.edu
Fabricio d'Almeida

Krannert School of Management

Purdue University

545 KRAN

403 W. State St.

West Lafayette, IN 47907

fdalmeid@purdue.edu

Gaurav Kankanhalli

Joseph M. Katz Graduate School of Business

University of Pittsburgh

226 Mervis Hall

Pittsburgh, PA 15260

gkankanhalli@katz.pitt.edu 


\section{Introduction}

On June 23, 2016, voters in the United Kingdom elected to leave the European Union. The outcome of the Brexit referendum was surprising since most opinion polls had the "remain" vote winning by safe margins. Perhaps most notable was the notion that voters went to polling stations with little understanding about what casting a ballot for Brexit would entail. Leaving the EU would irrevocably change the status of the UK in European trade and customs agreements. It would change the status of European workers in the UK and that of British workers in continental Europe. Brexit would trigger renegotiations of decades-old agreements running a gamut from legal jurisdiction authority and trade to border restrictions and the fight against terrorism.

Rising political uncertainty appears to be a global phenomenon. This can be gleaned from the annotated time series of the policy uncertainty index calculated by Davis (2017); see Figure 1. Even in light of events such as the Global Financial Crisis and the Iraq War, the Brexit referendum brought about a pronounced spike in global uncertainty. That referendum was not part of an institutional mandate or predetermined political cycle (such as the election of new administrations in the US). Instead, it was an ad hoc consultation of the public's sentiment about an important international agreement, conducted for political leverage by Prime Minister David Cameron. Formally, Brexit had no immediately binding mandate. It would simply initiate a process by which the UK would ask the EU to negotiate an exit (trigger EU's Article 50). Once this process was set in motion (at a date to be later determined), the parties would have years to design new rules governing their relations. The Brexit vote outcome has arguably triggered a fundamental change to the ways agents would form expectations about trade, capital, and labor markets going forward. ${ }^{1}$

Events like Brexit are seemingly more frequent in a world gone wary of the workings of the global financial markets, international trade, and migration. ${ }^{2}$ These are phenomena of much interest, yet of poorlyunderstood consequences. This paper sheds novel light into an array of cross-border connections between political uncertainty and economic activity. It does so gauging the impact of the 2016 Brexit vote on businesses located outside of the UK-EU geographical boundaries; in particular, firms domiciled in the United States. The US economy serves as a candidate to study the cross-border effects of Brexit for several reasons.

\footnotetext{
${ }^{1}$ This sentiment is made explicit in public remarks by Mark Carney, the Governor of the Bank of England: "Brexit is a regime shift that has markedly changed the possible outcomes for the UK economy...affecting how agents (households, businesses and financial markets) react, particularly the extent to which they are affected by uncertainty during the negotiations and the degree to which they anticipate any outcome and pull forward."

${ }^{2}$ The surprising election of Donald Trump in the United States is said to be rooted in voter sentiment that finds close parallels in Brexit (see Becker et al. (2017)). Similar manifestations of that sentiment have emerged in various forms in France, Italy, Spain, and Brazil, among others, in recent years.
} 


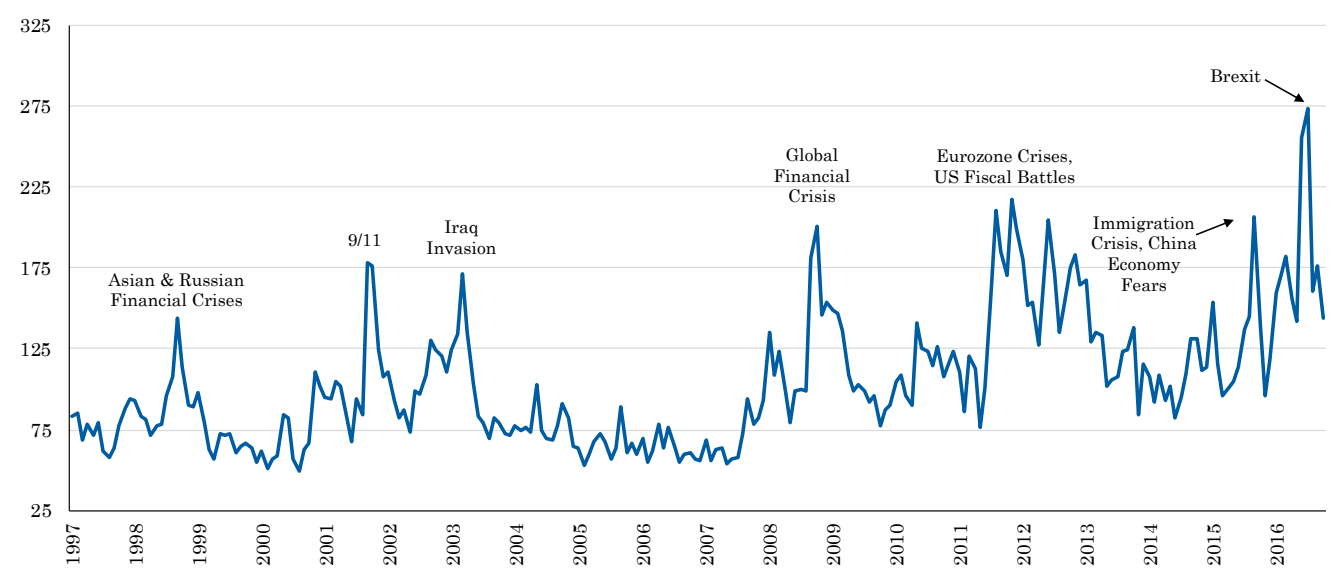

Figure 1. Global Economic Policy Uncertainty. This figure is a reproduction of Figure 1 in Davis (2017), which computes a GDP-weighted average of monthly Global Economic Policy Uncertainty based on Baker et al. (2016).

First, while EU-ties are at the root of Brexit, and effects observed across European economies may be endogenous to the referendum itself, this is plausibly not true of the US. Second, there exist long-standing, strong ties between the US and UK economies, making potential outcomes more easily measurable. ${ }^{3}$ Finally, it is uniquely informative to look at the world's largest economy to gauge the global impact of a consequential event like Brexit.

We begin our study on the potential firm-level externalities of events like Brexit by establishing relevant microeconomic underpinnings. Within a real-options framework, we first sketch out a negative relation between uncertainty and firm job creation, as well as fixed capital investment and divestitures, as firms have a greater incentive to "wait-and-see" before committing to these decisions. The framework predicts stronger effects for firms with higher labor (capital) adjustment costs on employment (investment). We also model the impact of uncertainty on "growth options" activities, such as R\&D investing. We uniquely show how these activities are positively affected by aggregate uncertainty. The framework we study is important in that it provides predictions for second-moment ("uncertainty") shocks onto a wide range of corporate decisions, notably employment and R\&D, independent of changes to first-moment expectations (e.g., "bad news").

We derive testable predictions from the framework to examine how "UK-exposed" firms in the US (identified through market- and textual-search-based measures) conduct decisions regarding investment, divestitures, employment, and $R \& D$ spending in the aftermath of the 2016 Brexit vote. Using forward-looking financial analysts' forecast data, we find that there was no decline in the expected profitability of UK-exposed firms, but an increase in profit dispersion — suggesting that Brexit embedded a "second-moment" innova-

${ }^{3}$ The UK is the $5^{\text {th }}$ top destination of US exports and the $7^{\text {th }}$ top US import partner. BIS data show that the US banking system has its strongest links with banks from the UK, and vice-versa. 
tion. We subsequently use an empirical approach that allows for Brexit potentially having both first- and second-moment effects on US firms. Our base difference-in-differences estimates show that in the last two quarters of 2016 alone, the investment-to-assets rates of UK-exposed firms fell by 0.16 percentage points more than the investment rates of comparable non-UK-exposed firms. Given that the average quarterly investment rate in 2015 was $1.1 \%$ of assets, this decline represents a drop of $15 \%$ in baseline investment spending. UK-exposed firms also reduced their divestitures by nearly $30 \%$ of the average annual rate. Consistent with our theoretical framework, we also observe an increase in R\&D spending by UK-exposed firms following the Brexit vote. Specifically, those firms increased their R\&D-to-asset ratios by 0.2 percentage points more than non-UK-exposed firms in the second half of 2016, implying an increase of $7 \%$ in annual R\&D spending. Looking at employment, our estimations show that labor force growth declined from $3.4 \%$ in 2015 to $-1.5 \%$ for UK-exposed firms in 2016. That is, the Brexit vote outcome led to a slowdown in net job creation among UK-exposed firms in the United States.

We set out to characterize our findings on US companies' investment and employment decisions following the Brexit vote by identifying whether those decisions affected their US-based operations or their foreign-based operations using establishment-level employment data. We find that investment cuts and jobs losses took place within US borders. We further examine the workforce characteristics of the firms in our sample. Our tests show that workers with lower skills are those most likely to be terminated by firms hit by UK-borne uncertainty. Brexit also affected UK-exposed firms' establishment turnover decisions, with the opening and closures of US establishments falling by around $2 \%$.

We finally delve into an analysis of offshoring activities in our sample firms. This analysis reveals that investment cuts are undertaken primarily by US firms with a high degree of input (rather than output) offshoring activity with the UK. The evidence we present shows that the 2016 Brexit vote had a meaningful, multifaceted impact on the US labor market.

Along the lines of our framework, we also find that the investment behavior of UK-exposed firms was modulated by capital adjustment costs. Specifically, the investment drop caused by the Brexit vote was a function of the nature of the assets US firms operated - it was more acute for firms in industries where fixed capital is highly irreversible (non-redeployable). Labor adjustment costs also seemed to modulate the extent to which UK-exposed firms hired and fired workers. In particular, exposed firms in industries with higher unionization rates — where workforce adjustments are costlier — registered a significantly lower job growth. 
Looking beyond investment and employment, we examine several auxiliary firm policies and find that UK-exposed firms also saved more cash and accumulated less inventory (non-cash working capital) in the aftermath of the Brexit vote. Our estimates imply that following the vote, UK-exposed firms increased their cash holdings by $12 \%$ relative to their baseline level. The results we report are in line with literature on corporate liquidity management suggesting that, in times of heightened volatility, firms with higher market exposure are likely to increase liquid asset holdings for precautionary reasons (e.g., Acharya et al. (2013)).

Throughout our analysis, we strive to account for the larger context in which Brexit affected US firms. For example, one of the immediate effects of the Brexit vote was a 9\% depreciation of the British pound relative to the US dollar. We verify that virtually all firms in our sample report using derivatives to hedge against foreign exchange (FX) risk. In addition, we design our tests so they are unconfounded by FX fluctuations. ${ }^{4}$ Nonetheless, we control for possible heterogeneous effects of the pound depreciation on UK-exposed firms in several ways. Our results are robust to the inclusion of FX exposure metrics, suggesting that the 2016 Brexit vote entailed an unhedgeable source of economic uncertainty to American corporations, beyond hedgeable fluctuations in FX markets.

Our results are also robust to several alternative testing strategies, including alternative firm-level measurements of exposure to UK uncertainty, sampling periods, estimation methodologies, and falsification checks. For example, DID analyses featuring the exclusion of Trump's election or focusing on the election of David Cameron suggest that the increase in uncertainty brought about by the Brexit vote is the reason behind the documented behavior of UK-exposed American firms around June 2016. We also find no change in investment by US firms exposed to major trading partners (such as China, Mexico, Japan, India, and Brazil) that did not witness significant increases in uncertainty at the same time of the 2016 vote. Our results also continue to hold when we use non-parametric propensity score matching estimations. Finally, our investigation also accounts for the role of various alternative channels. In a set of robustness tests, we consider whether tightening financing constraints for UK-exposed firms in the wake of the Brexit vote played a role in explaining the effects we observe. We utilize a number of metrics that speak to firms' ability to raise funding following the Brexit vote (e.g., bond yields and loan spreads) and re-estimate our models with their inclusion. We also consider whether a concurrent adoption of automation technologies by UK-exposed firms

\footnotetext{
${ }^{4}$ Since both our treatment and control groups comprise firms domiciled in the US, any homogeneous effects of the pound depreciation on US firms are differenced out in our estimations. Notably, as demonstrated in our offshoring analysis, most affected firms had input-based relationships with the UK. To the extent that the pound depreciation has any heterogeneous effects, it would act as a positive shock to importing firms' cash flows, which would be consistent with such firms disproportionately increasing — instead of cutting — their investment and hiring.
} 
may explain the simultaneous drops in capital investment and hiring, and increases in R\&D expenditures. We rely upon novel geographic- and text-based proxies of firms' exposures to automatization, and show that our findings continue to obtain controlling for their presence.

Our study builds upon a growing literature on the effects of political uncertainty. Macroeconomic studies on uncertainty and real activity include recent contributions by Bloom (2009) and Bloom et al. (2018). Work on the effect of uncertainty on corporate investment and bank lending include Julio and Yook (2012), Gulen and Ion (2016), and Berg et al. (2019). Our paper advances the existing literature on several fronts, but particularly as we focus on the international transmission of uncertainty, rather than on its domestic effects. The literature is particularly silent on the international transmission of uncertainty at the firm level, which limits our knowledge on how domestic firms respond to foreign-born uncertainty events and which mechanisms aggravate these responses. ${ }^{5}$ On that dimension, our paper goes beyond aggregate evidence and sheds light on the micro-level mechanisms that led US firms to cut American jobs and investment in response to a foreign-born political event. This, while being prompted to seek innovation. Through our analysis, we uncover the importance of US firms' input exposures, which drive the bulk of corporate investment cuts following Brexit. Our establishment-level employment data are further informative about how job destruction and establishment turnover operated inside US borders in the aftermath of the 2016 UK vote. ${ }^{6}$ As the British anti-integration referendum has reportedly inspired similar national-centric movements in several other countries, it is important that researchers and policy makers are able to gauge its economic implications.

\footnotetext{
${ }^{5}$ Studies on international spillover effects of policy uncertainty have focused on aggregate, time-series evidence (e.g., Klössner and Sekkel (2014) and Bernal et al. (2016)). Another strand of the literature focuses on the effects of policy uncertainty on FDI flows (Azzimonti (2016) and Julio and Yook (2016)). Recently, Hassan et al. (2020) study the international effects of Brexit relying exclusively on firms' "conference calls" to gauge their exposure to Brexit. In contrast to Hassan et al. (2020), our textual analysis of mandatory $10-\mathrm{K}$ filings is complemented by a market-based approach in order to comprehensively gauge a firm's exposure to events in the UK. We choose not to rely on conference calls in light of evidence on severe problems with the information content of such calls. For instance, the voluntary nature of conference call disclosures leads to a wide range of selection issues that compromises the classification of firms' risk exposures. Among others, it has been documented that managers selectively refrain from answering questions from participants on the calls (Hollander et al. (2010)), shape the content of calls based on firm performance (Matsumoto et al. (2011)), as well as venue location, industry focus, and audience size (Bushee et al. (2011)).

${ }^{6}$ Our establishment-level data allows us to transparently observe employment within US borders. This is in contrast to recent papers that rely on employment data from COMPUSTAT (e.g., Hassan et al. (2020)). Critically, COMPUSTAT aggregates data on workers from all foreign affiliates (including those located in the UK), confounding employment results as a mix of both the international and the domestic effects of Brexit.
} 


\section{Background on the 2016 Brexit Referendum}

The 2016 Brexit referendum is said to be rooted in long-standing political and social tensions within Europe, fueled by nationalistic and populist movements in the UK (see, e.g., Becker et al. (2017)). In the early 2000s, attempts by the EU to deepen integration among its members sparked British opposition against the oversight of a supranational entity. The rise of the UK Independence Party (UKIP) captured this sentiment. As Britons voted for representatives in the EU parliament, the UKIP achieved the third place in 2004, second in 2009, and first in 2014. This was the first time in modern British history that a party other than the Labour or Conservative parties took the largest share of a nation-wide election. Facing the rise of the UKIP in 2013, Prime Minister David Cameron announced a contingent (non-binding) plan: If the Conservative Party were to win the general elections of May 2015, he would commit to a referendum on Britain's membership in the EU before 2017. Granted another term on a narrow victory, Cameron fulfilled his electoral promise, and on June 2015 the House of Commons approved the European Union Referendum Act. Appendix D presents a timeline of events leading to the UK-EU referendum ("Brexit").

David Cameron was against the UK's exit from the EU and vowed to resign if Brexit passed. On February 20,2016 , he announced that voting would take place on June 23,2016 . In the months leading up to the referendum, the polls indicated that the chances of the UK leaving the EU were slim. A few weeks before the referendum, the "leave" vote led for the first time, only to trail again after the assassination of a "remain" supporter (Labour MP Jo Cox) by a "leave" extremist. On the eve of the referendum, bookmakers' odds showed chances of more than $90 \%$ that the UK would remain in the EU. The vote result prompted Cameron's immediate resignation.

The political upheaval around the Brexit referendum process was unprecedented. The uncertainty it generated regarding economic policy in the UK can be gauged from the Baker et al. (2016) EPU index (see Figure 2). The average quarterly UK EPU index before 2016 was 133 (starting from the beginning of the modern series in 1997). The index jumped by 410 points in 2016 - nearly four times the baseline average, or a 3.4-standard deviation from the series. Although the June 23 vote resolved the uncertainty about the referen-

dum per se, Brexit's nonbinding mandate and unspecified procedures were still problematic. Under Prime Minister Theresa May, it became clear that conditions under which the UK would leave the EU regarding agreements on trade, migration, and financial relations, among others, remained unsettled. Voicing her intention to proceed with the will of the voters, Prime Minister May triggered the formal exit process provided by Article 50 of the Lisbon Treaty on March 29, 2017. 


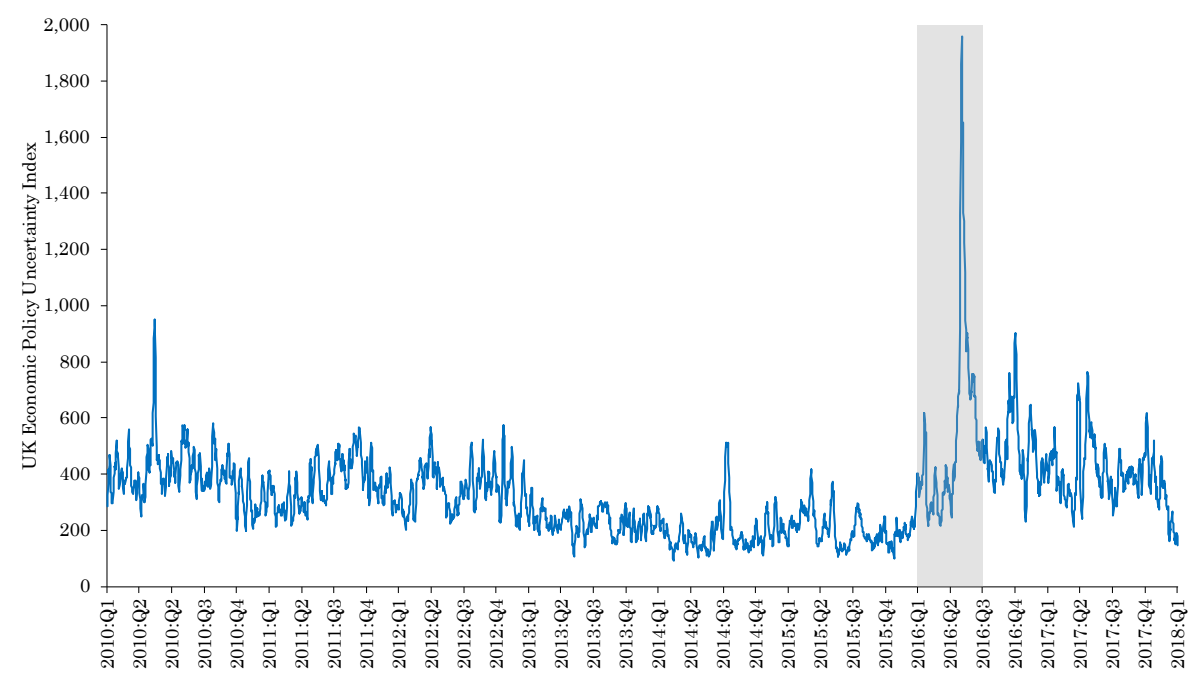

Figure 2. UK Economic Policy Uncertainty (2010-2017). The figure shows a 7-day moving average of the Economic Policy Uncertainty index of Baker et al. (2016) for the UK. The shaded area marks the period of Brexit-related events, starting with the February 2016 announcement of the date of the referendum.

\section{Theoretical Framework}

We develop a simple theoretical framework to guide our tests of the impact of uncertainty on various types of corporate activity. To this end, we characterize increases in uncertainty using the concept of meanpreserving spread (MPS). ${ }^{7}$

\subsection{Set Up}

Consider the investment decision of a firm, $i$, that operates for three periods, $t=0,1$, and 2 . The firm chooses whether and when to invest in two types of projects: standard-type investments ("capital" or "labor") and growth option-type investments (“R\&D”). The menu of potential capital investment projects is indexed by $n$, which lies on the interval $[0, N]$. The menu of potential R\&D projects is indexed by $m$, on the interval $[0, M]$. The firm has an endowment of existing capital investment projects that it had invested in prior to $t=0$. The menu of existing projects is indexed by $w$, on the interval $[0, W]$. There is no time discounting.

\footnotetext{
${ }^{7}$ An uncertainty-increasing MPS only requires that a zero-mean, non-degenerate source of randomness has been added to the distribution of the uncertain outcome. This approach allows us to derive a set of results that hold with generality, while remaining agnostic about the functional forms governing the distribution and moments of the outcomes of interest (see also Lee and Shin (2000)).
} 


\subsubsection{Investment Income}

If the firm decides to invest in a capital project $n$, its income at $t=1,2, v_{i t}^{(n)}>0$, is an IID random variable:

$$
v_{i t}^{(n)}=v_{i t}=\beta_{i} V_{t}+\epsilon_{i t} .
$$

If the firm decides to invest in a R\&D project $m$, its income at $t=1,2, u_{i t}^{(m)}>0$, is:

$$
u_{i t}^{(m)}=u_{i t}=\beta_{i} V_{t}+\xi_{i t}
$$

Finally, the firm's income from disinvesting (selling) an existing project from its capital endowment, $w$, at $t=1,2$, is denoted by $s_{i t}^{(w)}>0$, such that:

$$
s_{i t}^{(w)}=s_{i t}=\beta_{i} V_{t}+\zeta_{i t} .
$$

In this setting, $V_{t}>0$ represents the time-varying aggregate demand curve facing the firm and $\beta_{i} \in(0,1]$ is the firm's sensitivity to demand. $\epsilon_{i t}, \xi_{i t}$, and $\zeta_{i t}$ are independent, idiosyncratic, mean-zero shocks, with variances $\sigma_{\epsilon}^{2}, \sigma_{\xi}^{2}$, and $\sigma_{\zeta}^{2}$, respectively. $V_{t}$ is distributed as $V_{t} \sim G\left(\overline{V_{t}}, r\right)$, where the mean of $V_{t}$ is equal to $\overline{V_{t}}$, the variance is equal to $\sigma^{2}(r)$, and $r$ is an index of the mean-preserving spread. Specifically, $r^{\prime}>r \Longrightarrow$ $G\left(\cdot, r^{\prime}\right)$ is a MPS of $G(\cdot, r)$ and $\int V_{t} d G(\cdot, r)=\overline{V_{t}} \forall r$.

The firm's revenue from each capital investment project it decides to invest in can be characterized as a MPS with distribution $v_{i t} \sim P\left(\overline{v_{i t}}, r\right)$ and mean $\overline{v_{i t}}=\beta_{i} \times \overline{V_{t}}$, with variance $\sigma_{i}^{2}(r)=\beta_{i}^{2} \times \sigma^{2}(r)+\sigma_{\epsilon}^{2}$. Likewise, each R\&D project's revenue can be characterized as a MPS with distribution $u_{i t} \sim Q\left(\overline{u_{i t}}, r\right)$ and mean $\overline{u_{i t}}=\beta_{i} \times \overline{V_{t}}$, with variance $\omega_{i}^{2}(r)=\beta_{i}^{2} \times \sigma^{2}(r)+\sigma_{\xi}^{2}$. Finally, the proceeds from disinvesting each existing project can be characterized as a MPS with distribution $s_{i t} \sim R\left(\overline{s_{i t}}, r\right)$ and mean $\overline{s_{i t}}=\beta_{i} \times \overline{V_{t}}$, with variance $\psi_{i}^{2}(r)=\beta_{i}^{2} \times \sigma^{2}(r)+\sigma_{\zeta}^{2}$.

\subsubsection{Investment Costs}

In order to undertake investment project $n$, the firm must incur a one-time fixed cost of capital, denoted by $F_{i K}(\kappa, n)=\kappa n$, and a one-time fixed cost of labor, denoted by $F_{i L}(\lambda, n)=\lambda n$. The parameters $\kappa>0$ and $\lambda>0$ capture the degree of irreversibility of input fixed costs, which scale with $n$. If it chooses to invest in capital project $n$, the firm can either invest at $t=0$ or $t=1$. If it invests in $n$ at $t=0$, it incurs the fixed costs $\lambda n+\kappa n$ at $t=1$, and earns the revenues $v_{i 1}+v_{i 2}$. If it does not invest at $t=0$, choosing instead to invest at $t=1$, it incurs the fixed costs $\lambda n+\kappa n$ at $t=2$, earning the revenue $v_{i 2}$. The negative effect of uncertainty on capital investment arises from the joint presence of the option to delay and irreversible fixed costs. 
Growth-option-type projects, $m$, differ from capital investment-type projects, $n$, in two key ways. First, the option to invest in these projects is only available at $t=0$. That is, the firm has only one chance to decide whether to invest. If it declines, these projects cease to become available in the future ( $t=1$ or 2$)$. To a firstorder approximation, this matches the reality of several types of R\&D projects, including the "race to patent" a certain idea or bring a new technology to the market. Second, the firm is able to stage its investment in the projects. If the firm wishes to buy the option to invest in $m$ projects, it pays an upfront cost of $m^{\alpha}$, which is convex in the size of its R\&D portfolio (i.e., $\alpha>1$ ). In addition, it must pay a development cost $d_{t}$ for each period in which the project remains alive. That is, in order to earn $t=1$ revenue $u_{i 1}$, it must pay $d_{1}$; similarly, in order to earn $t=2$ revenue $u_{i 2}$, it must pay $d_{2}$. However, at $t=1$, the firm observes the first-stage revenue, $u_{i 1}$, which serves as a signal of the second-stage revenue of the project. ${ }^{8}$ Based on this signal, the firm may choose either to abandon the project at the end of $t=1$, or invest and take it to completion at $t=2$. In the former case, it does not receive any revenue from the project at $t=2$; i.e., $u_{i 2}=0$. On the other hand, if at the end of $t=1$, it chooses to continue the project then it must pay the second period development cost, $d_{2}$, to receive $u_{i 2}$. This, too, matches the reality of certain types of R\&D projects (e.g., pharmaceutical trials and corporate venture capital funds), in which decisions are made in stages, and the firm does not need to pre-commit to follow through on all stages at once. Notably, the joint absence of (1) the option to delay and (2) irreversible, fixed costs generates a positive effect of uncertainty on R\&D investment. ${ }^{9}$

Finally, the firm can choose at time $t=0$ or $t=1$ to disinvest (sell) any of its existing endowment of projects, $w$. If the firm sells a project at time $t$, it must pay a scrapping $\operatorname{cost} \delta w$, but receives the cash flow from disinvestment of $s_{i t}$. Else, for each period $t$ that the project remains alive, the firm earns a known $x_{i t}$ (for example, rent accruing from a real-estate holding). The process of disinvesting a project is irreversible, and as with capital investment, this irreversibility induces a negative effect of uncertainty on disinvestment.

\subsection{Model Analysis and Results}

In what follows, we present analysis and results corresponding to the firm's standard investment problem and R\&D decision. ${ }^{10}$

\footnotetext{
${ }^{8}$ As noted in Section 3.1.1, the revenues at the first and second stages both have a common component, driven by $\beta_{i}$, and an idiosyncratic, mean-zero, IID component. As a result, the first-stage revenue is a noisy but unbiased signal of the second-stage revenue.

${ }^{9}$ This modeling is consistent with theories showing a positive effect of uncertainty on growth-options-type investment (see, e.g., Bar-Ilan and Strange (1996, 1998), Grossman and Shapiro (1986), and Kulatilaka and Perotti (1998)).

${ }^{10}$ In Appendix A, we model the firm's decision to disinvest and derive results on the cross-sectional implications of the role played by the degree of input irreversibility. Proofs of propositions and lemmas are in Appendix B.
} 


\subsubsection{Capital and Labor Investment Decisions}

In solving the firm's capital investment problem, we first consider its decision at $t=1$. If the firm had initiated any projects at $t=0$, it obtains the second period revenue $v_{i 2}$ per project. Among those projects that were not undertaken at $t=0$, the firm can choose to initiate any of them at $t=1$ and earn $v_{i 2}-(\kappa+\lambda) n$ per project. Else, it can discard any uninvested projects and earn 0 . The firm will rationally discard a given project, $\tilde{n}$, when its expected revenue is less than the associated costs of investment and hiring. The firm will cease operations at the end of $t=2$ and any project that is not undertaken at either $t=0$ or $t=1$ has a value of 0 by the end of $t=2$. The firm's investment decision at $t=1$ will be guided by profit in the second period that is generated by project $\tilde{n}$. The profit function, $\pi_{i 2}$, can be characterized as:

$$
\pi_{i 2}(\tilde{n})=\left\{\begin{array}{lll}
v_{i 2} & (\text { Early Investment }) \\
v_{i 2}-(\kappa+\lambda) \tilde{n} & \text { if } v_{i 2}>(\kappa+\lambda) \tilde{n} & (\text { Delayed Investment }) \\
0 & \text { if } v_{i 2} \leq(\kappa+\lambda) \tilde{n} & (\text { No Investment })
\end{array}\right.
$$

Next, we consider the firm's decision at $t=0$. The optimal total investment level at $t=0$ can be expressed in terms of $n^{*}$, the breakeven project. The firm will invest in all projects in the range $\left[0, n^{*}\right)$, and not invest in projects in the range $\left[n^{*}, N\right]$, instead waiting until $t=1$ to decide whether to undertake any of those projects. The firm's expected profit from investing in project $\tilde{n}$ at $t=0$ is $v_{i 1}+\mathbb{E}\left[v_{i 2}\right]-(\kappa+\lambda) \tilde{n}$. Its expected profit from not investing in $\tilde{n}$ at $t=0$, and choosing instead to wait until $t=1$ to decide, is $\mathbb{E}\left[\max \left(v_{i 2}-(\kappa+\lambda) \tilde{n}, 0\right)\right]$. The firm invests in project $\tilde{n}$ at $t=0$ if:

$$
\underbrace{v_{i 1}+\mathbb{E}\left[v_{i 2}\right]}_{\text {Expected Revenue }} \geq \underbrace{(\kappa+\lambda) \tilde{n}}_{\text {Cost of Investment }}+\underbrace{\mathbb{E}\left[\max \left(v_{i 2}-(\kappa+\lambda) \tilde{n}, 0\right)\right]}_{\text {Value of Waiting }} .
$$

The breakeven condition for determining the optimal investment level $n^{*}$ at $t=0$ is:

$$
v_{i 1}+\mathbb{E}\left[v_{i 2}\right]=(\kappa+\lambda) n^{*}+\mathbb{E}\left[\max \left(v_{i 2}-(\kappa+\lambda) n^{*}, 0\right)\right]
$$

In Lemma 1, we prove the existence of the optimal $t=0$ investment level, $n^{*}$.

Lemma 1. The optimal capital investment level $n^{*}$ at $t=0$ is given by (6) for sufficiently large $N$.

The breakeven condition in (6) implies that the firm invests in all projects at $t=0$ up to project $n^{*}$, for which the benefits are expected to exceed the costs. The embedded optionality in the firm's investment decision is key in generating a negative relation between uncertainty and investment. An increase in uncertainty in the distribution of $v_{i t}$ reduces the breakeven project level $n^{*}$, and correspondingly shrinks the set of projects the firm invests in at $t=0$, namely the interval $\left[0, n^{*}\right)$. We establish this result in Proposition 1. 
Proposition 1. Increased uncertainty leads to less investment at $t=0$. For $r^{\prime}>r$, namely when $G\left(\cdot, r^{\prime}\right)$ is obtained by a mean-preserving spread of $G(\cdot, r), n^{*}\left(r^{\prime}\right)<n^{*}(r)$. That is, $\frac{d n^{*}}{d r}<0$.

Given that the firm invests in $n^{*}$ projects, the variance of its total income is $\left(n^{*} \times \sigma_{i}(r)\right)^{2}$. Notice that $r^{\prime}>$ $r$ implies that variance of the firm's total income increases; i.e., $\left(n^{*} \times \sigma_{i}\left(r^{\prime}\right)\right)^{2}>\left(n^{*} \times \sigma_{i}(r)\right)^{2}$. In addition, for $\beta_{i}^{\prime}>\beta_{i}$, it follows that $\left(n^{*} \times \sigma_{i}^{\prime}(r)\right)^{2}=\left(n^{*}\right)^{2} \times\left(\beta_{i}^{\prime 2} \times \sigma^{2}(r)+\sigma_{\epsilon}^{2}\right)>\left(n^{*}\right)^{2} \times\left(\beta_{i}^{2} \times \sigma^{2}(r)+\sigma_{\epsilon}^{2}\right)=\left(n^{*} \times \sigma_{i}(r)\right)^{2} \forall r$. That is, the higher $\beta_{i}$, the greater the increase of firm $i$ 's income variance for a given increase in uncertainty.

\subsubsection{R\&D Investment Decisions}

Consider the firm's decision at $t=0$, when it may opt to invest in a portfolio of R\&D projects. The profits from a $R \& D$ portfolio of size $\tilde{m}$ can be expressed as:

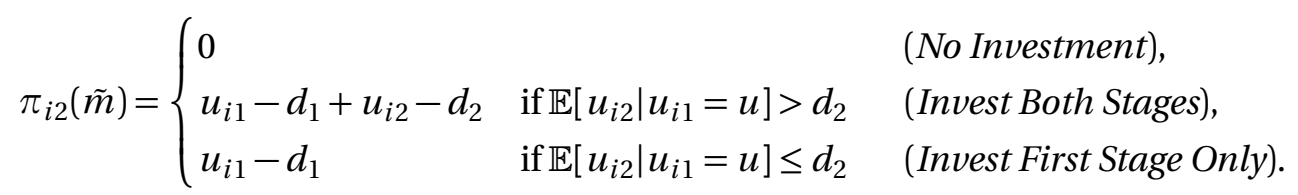

The firm will invest in a portfolio of R\&D projects of size $m$ at $t=0$ to maximize the following:

$$
\max _{m} m \times \mathbb{E}\left[\max \left(u_{i 2}-d_{2}, 0\right)\right]+m u_{i 1}-m d_{1}-m^{\alpha} .
$$

The first-order condition of Eq. (8) implicitly defines the optimal R\&D portfolio size, $m^{*}$, by the following:

$$
\mathbb{E}\left[\max \left(u_{i 2}-d_{2}, 0\right)\right]+u_{i 1}=d_{1}+\alpha m^{* \alpha-1} .
$$

Noting that the first-stage revenue, $u_{i 1}$, is a noisy but unbiased signal of the second-stage revenue, $u_{i 2}$, and assuming that these variables are normally distributed, we can simplify Eq. (9) as: ${ }^{11}$

$$
\begin{gathered}
\mathbb{E}\left[u_{i 1}-d_{2} \mid u_{i 1}>d_{2}\right]+u_{i 1}=d_{1}+\alpha m^{* \alpha-1}, \\
\overline{u_{i 1}}+\frac{\sqrt{\omega_{i}^{2}(r)+\sigma_{x}^{2}}}{1-\Phi\left(\frac{d_{2}-\overline{u_{i 1}}}{\sqrt{\omega_{i}^{2}(r)+\sigma_{x}^{2}}}\right)}\left[\phi\left(\frac{d_{2}-\overline{u_{i 1}}}{\sqrt{\omega_{i}^{2}(r)+\sigma_{x}^{2}}}\right)\right]+u_{i 1}=d_{1}+d_{2}+\alpha m^{* \alpha-1} .
\end{gathered}
$$

In Lemma 2, we prove the existence of the optimal R\&D investment level $m^{*}$.

Lemma 2. The optimal $R \& D$ investment level $m^{*}$ at $t=0$ is given by (10) for $\alpha>1$.

The breakeven condition in (10) implies that the firm invests in a portfolio of R\&D projects up to the point at which benefits are expected to exceed costs. Since at $t=1$ the firm can (upon observing a signal

\footnotetext{
${ }^{11}$ We assume (w.l.o.g) normality for analytical tractability. This allows us to write $u_{i 2}$ as $u_{i 1}$ plus an IID zero-mean normal noise with variance $\sigma_{x}^{2}$ and to provide a closed-form expression for the firm's breakeven R\&D project in Eq. (10).
} 
of the projects' future revenues), choose to abandon any project, and if so, avoid paying the second-stage development cost, the decision to invest in the $\mathrm{R} \& \mathrm{D}$ projects at $t=0$ is equivalent to the decision to buy a portfolio of call options expiring at $t=1$. At the breakeven R\&D investment level, $m^{*}$, the price of the option equals its value. Increased uncertainty in the distribution of $u_{i t}$ increases the value of this option, thereby increasing the breakeven project threshold $m^{*}$, expanding the set of R\&D projects the firm undertakes. This argument is formalized in Proposition 2.

Proposition 2. Increased uncertainty leads to greater $R \& D$ investment at $t=0$. For $r^{\prime}>r$, namely when $G\left(\cdot, r^{\prime}\right)$ is obtained by a mean-preserving spread of $G(\cdot, r), m^{*}\left(r^{\prime}\right)>m^{*}(r)$. That is, $\frac{d m^{*}}{d r}>0$.

Proposition 2 states that an increase in uncertainty increases the set of R\&D-type projects that the firm is willing to undertake, given that the potential upside has increased and the downside is capped by the ability to abandon a project upon observing an interim signal as to its future profitability, and avoid paying part of the investment costs. This is in contrast to capital investment, whose initial costs, once paid, are largely lost.

It is worth concluding our theoretical analysis with a discussion contrasting "uncertainty" about future cash flows and "expectations" about future cash flows. A decline in expected cash flows produces similar implications in terms of a decline in capital investment and employment. Notably, however, a decline in expected cash flows provides contrasting implications in terms of an increase in disinvestment and a decline in $R \& D$, counter to the effects of increased uncertainty on these decisions predicted by our framework.

\subsection{Testable Predictions}

Our framework implies that an increase in aggregate uncertainty reduces firm investments in standard-type projects, and that the effect is modulated by the degree of exposure to uncertainty, $\beta_{i}$. In the context of the impact of UK-born uncertainty onto US-based firms, we state our first testable prediction.

Prediction 1. American firms with a higher exposure to UK uncertainty (High UK-Exposure firms) will disproportionately reduce their investment in capital and labor in response to the Brexit vote.

Our analysis also indicates that an increase in aggregate uncertainty triggers firm investment in R\&Dtype projects through a growth-options channel, and the effect is modulated by the degree of exposure to uncertainty, $\beta_{i}$. Translating this to our test setting, we state our second testable prediction. 
Prediction 2. American firms with a higher exposure to UK uncertainty (High UK-Exposure firms) will disproportionately increase their investment in $R \& D$ in response to the Brexit vote.

The theoretical framework further implies that an increase in aggregate uncertainty reduces firm capital disinvestment, and the effect is modulated by the degree of firm-level exposure to uncertainty. This translates into our third testable prediction.

Prediction 3. American firms with a higher exposure to UK uncertainty (High UK-Exposure firms) will disproportionately reduce their disinvestment in fixed capital in response to the Brexit vote.

Finally, the negative relationship between uncertainty and investment is affected by fixed costs $F_{i K}$ and $F_{i L}$, which capture the degree of irreversibility of capital and labor, respectively. It implies that higher input adjustment costs in each factor modulates the effect of uncertainty in investment in that input. This gives rise to our fourth and fifth testable predictions.

Prediction 4. American firms with a higher exposure to UK uncertainty (High UK-Exposure firms) facing higher capital adjustment costs will reduce their capital investment more pronouncedly in response to the Brexit vote.

Prediction 5. American firms with a higher exposure to UK uncertainty (High UK-Exposure firms) facing higher labor adjustment costs will reduce their hiring more pronouncedly in response to the Brexit vote.

In the next section, we translate the above predictions into their empirical counterparts, describe our data, and lay out associated test strategies.

\section{Data and Methodology}

\subsection{Empirical Counterparts}

The implementation of our tests calls for identifying empirical counterparts to the constructs of the our theoretical framework. We first introduce an empirical counterpart to the sensitivity parameter $\beta_{i}$, which captures individual firms' responses to changes in aggregate uncertainty. We adopt two approaches. The first follows the framework very closely, yielding an empirical proxy for $\beta_{i}$ that is derived from the capital markets. The second is based on expectations of corporate decision-makers regarding uncertainty, taken 
from firms' disclosures to market investors. ${ }^{12}$ After defining empirical counterparts for $\beta_{i}$, we present measures of capital and labor irreversibility, corresponding to $\kappa$ and $\lambda$, respectively.

\subsubsection{Theoretical Framework-Based Measure of Uncertainty}

In the context of our study, the increase in aggregate uncertainty, $V_{t}$, comes from the rise in uncertainty associated with the Brexit vote. Accordingly, we take variances on both sides of Eq. (1) (alternatively, Eq. (2)) to capture the notion of uncertainty in the MPS framework:

$$
\operatorname{Var}\left(v_{i t}\right)=\beta_{i}^{2} \operatorname{Var}\left(V_{t}\right)+\sigma_{\epsilon}^{2} .
$$

We can employ a regression-like approach to operationalize an empirical counterpart to $\beta_{i}$. Specifically, taking square-roots of both sides of (11) we obtain:

$$
\operatorname{Vol}\left(v_{i t}\right) \approx \beta_{i} \operatorname{Vol}\left(V_{t}\right)+\sigma_{\epsilon}-\sqrt{2 \times \beta_{i} \operatorname{Vol}\left(V_{t}\right) \times \sigma_{\epsilon}} .
$$

Following Bloom (2014), we use stock market volatility as a gauge of aggregate uncertainty and estimate (12) for each firm $i$ as: ${ }^{13}$

$$
\operatorname{Vol}\left(r_{i t}\right)=\alpha_{i}+\beta_{i}^{U K} \operatorname{Vol}\left(F T S E 100_{t}\right)+\theta \operatorname{Controls} s_{t}+\epsilon_{i t} .
$$

Eq. (13) uses the volatility of equity returns, $\operatorname{Vol}\left(r_{i t}\right)$, as a proxy for firm income volatility, $\operatorname{Vol}\left(v_{i t}\right)$. It also uses the volatility of the FTSE100 index as a proxy for uncertainty in the UK — the relevant source of aggregate uncertainty in our setting. We include control variables, Controls ${ }_{t}$, consisting of $\operatorname{Vol}(S P 500)$ and $\operatorname{Vol}\left(F X^{\$ / \varepsilon}\right)$ into (13) to absorb effects arising through firms' exposure to the domestic US market and exchange rate fluctuations between the US dollar and the British pound. For each firm, we take the estimated value of $\beta_{i}^{U K}$ from the above regression as the empirical counterpart to $\beta_{i}$ in our framework. ${ }^{14}$

\footnotetext{
${ }^{12}$ We also consider firm sales to the UK from accounting data sources like COMPUSTAT's Segment Files. However, careful examination of $10-\mathrm{K}$ forms shows that such data are often incomplete and inconsistently tabulated. Aggravating this problem, sales that take place in the UK are known to be invoiced in other countries (such as Ireland) for tax purposes. As such, our main analyses rely on information from other sources. In Section 5.2.2, however, we resort to an alternative textual-search-based analysis that goes beyond financial statements contained in $10-\mathrm{K}$ forms in identifying exposure to the UK (cf. Hoberg and Moon (2017)). That approach allows us to identify offshoring activities, as reported by firms in the text of their disclosures (information often missing from their tabulated financial statements).

${ }^{13}$ Bloom (2014) shows that stock market volatility exhibits a high degree of commonality with other observed proxies for uncertainty including those derived from bond markets, exchange rates, and GDP forecasts.

${ }^{14}$ The last term in (12) is subsumed by the idiosyncratic volatility term, $\epsilon_{i t}$, in (13). We note that the volatility of equity returns may be an imperfect proxy for the volatility of firm income as returns are driven by news on both cash flows and discount rates (Campbell and Shiller (1988)). Following Vuolteenaho (2002), we also decompose the volatility of each firm's returns into cash flow and discount rate components and re-estimate Eq. (13) with the cash flow component (only) as the dependent variable, obtaining an alternative uncertainty measure, $\beta_{i, C F}^{U K}$. The estimates for $\beta_{i}^{U K}$ and $\beta_{i, C F}^{U K}$ have a rank correlation of 0.8 , and there is an $86 \%$ overlap in the set of firms at the top tercile of both $\beta_{i}^{U K}$ and $\beta_{i, C F}^{U K}$. As shown in Table C.6, our inferences are unchanged whether using $\beta_{i}^{U K}$ or $\beta_{i, C F}^{U K}$ to conduct our tests.
} 


\subsubsection{Textual-Search-Based Measure of Uncertainty}

As an alternative measure of US firms' exposure to Brexit-induced uncertainty, we develop a textual-searchbased metric that is constructed by parsing firms' 2015 10-K filings. In particular, we look for the number of entries of keywords related to uncertainty about Brexit ("Brexit”, “Great Britain”, and "Uncertainty”) in firms' disclosures, classifying firms with a "high" number of entries as High UK-Exposure firms, and those with zero entries as control firms. ${ }^{15}$ Notably, the vast majority of firms file their 10-Ks with the SEC between between March and June of each year. By computing these wordcounts from firms' 10-K disclosures — before the actual vote takes place, yet after the referendum is announced - we build a measure of exposure to the UK based on what firms consider relevant to communicate to their investors on the eve of the 2016 Brexit vote.

Textual analysis reveals that most firms cite concerns about Brexit a half dozen times or more in their 10-Ks, or not at all. As such, we arbitrarily set a cut-off for high Brexit cites at more than 5 entries. There are 807 firms citing Brexit more than 5 times in their 10-Ks. On the other hand, 433 do not cite any Brexitrelated terms in their public filings. While the heuristic cut-off we consider is naturally arbitrary, our results are robust to many sensible alternative choices.

\subsubsection{Capital and Labor Irreversibility Measures}

Our predicted uncertainty-investment relationships are modulated by fixed costs $F_{i K}$, which capture the degree of irreversibility of capital. To empirically measure capital irreversibility, we use an index of capital redeployability proposed by Kim and Kung (2016). That index classifies fixed capital liquidity in terms of salability of assets in secondary markets. The premise is that when a firm operates assets that are used across several industries, there are more potential buyers should the firm decide to revert investment decisions by selling off its assets. The same is not true for a firm that operates highly-specialized assets. Higher values of the asset redeployability index are associated with a lower degree of capital irreversibility, corresponding to a lower value of $F_{i K}$ in our framework.

Our next task is to find an empirical proxy for the irreversibility of labor, $F_{i L}$. We resort to the use of worker unionization as an empirical proxy for frictions in labor input. We do so as ample research highlights the difficulties faced by firms with unionized employees in adjusting their workforce in response to changes in aggregate conditions (see, among others, Bloom (2009)). In using this strategy, we measure the

\footnotetext{
${ }^{15}$ Entries like “Referendum”, “Uncertain”, “United Kingdom”, “UK”, “U.K.”, “G.B.”, etc. are subsumed by the above wording.
} 
percentage of total employees who are unionized at the 4-digit SIC level using data from the BEA. We expect firms with a greater share of unionized workers to have lower labor flexibility and incur greater costs in adjusting the size of their workforce.

\subsection{Data Sources and Sample Construction}

We use COMPUSTAT Quarterly to gather basic information on firm investment and financial data. We consider US companies from the first calendar quarter of 2010 through the fourth quarter of 2016. We drop utility and financial firms, as well as companies whose market value or book assets are lower than $\$ 10$ million. The sample used in our baseline investment tests consists of 41,630 observations (firm-quarters). ${ }^{16}$ For additional analysis on firms' investment in the US, we obtain subsidiary-level investment data from the Bureau van Dijk's Orbis dataset (see Cravino and Levchenko (2016)). We use Orbis's company search tool to match parent firms in our COMPUSTAT sample to ultimate owner firms in Orbis. By doing so, we obtain separate information on their US- and UK-based subsidiaries. The Orbis sample we use consists of 6,203 observations (firm-years).

Firm-level employment data is taken from COMPUSTAT’s Annual Fundamentals. We measure employment growth based on the change in the number of employees of the firm. Our employment sample consists of 11,345 observations (firm-years). ${ }^{17}$ We rely on the Your-economy Time-Series (YTS) database, maintained by the Business Dynamics Research Consortium at the University of Wisconsin, for information on US-based employment. The YTS database is compiled from historical business files from Infogroup and are linked longitudinally to track establishment location, employment, and sales information at the establishment-year level for public and private firms in the US. We match our sample firms (both parents and their US subsidiaries) to YTS primarily using tickers, and augment this match through manual searches by firm name. The firms in our sample collectively operated 757,083 unique establishments, and this results in 1,809,301 establishment-year observations over the 2010-2016 period. We aggregate YTS employment growth at the firm level, giving a final US establishment-level employment growth sample of 11,345 firm-years.

We use CRSP stock price data and Bloomberg equity index and currency data to compute our theoretical framework-based measure of firm exposure to the UK (see Eq. (13)). We use monthly data from 2010:M1 through 2014:M12 so that exposure to the UK is measured before any major Brexit-related events. Analyst

\footnotetext{
${ }^{16}$ For details of the sample selection filters see Table C.1.

${ }^{17}$ The same filters described in Table C.1 are also applied to obtain this sample.
} 
forecast data are obtained from I/B/E/S. Data on bond yields are from TRACE and SDC, while syndicated loan spreads are drawn from WRDS-Reuters DealScan. Macroeconomic variables are taken from the Federal Reserve Bank of St. Louis' FRED database.

\subsection{Test Strategy and Empirical Specification}

\subsubsection{Identification}

We use a standard DID approach to assess the impact of the 2016 Brexit vote on American firms. Following our framework, in our base analysis, we characterize firms as treated (control) units if they are in the upper (bottom) tercile of the non-negative range of the $\beta_{i}^{U K}$ distribution. For group contrasting, we do not include

firms that benefit from uncertainty in the UK in the control group (firms with $\beta_{i}^{U K}<0$ ) as this could lead to overestimation biases attached to the treatment effects we seek to identify. Nevertheless, in specifications where we use $\beta_{i}^{U K}$ as a continuous treatment variable, we relax this restriction and include all values of $\beta_{i}^{U K}{ }^{18}$ Under this market-based approach a total of 449 unique firms are assigned to the treated category $\left(\beta_{i}^{U K}>0.68\right)$. In contrast, 360 unique firms are assigned to the control category $\left(\beta_{i}^{U K}<0.28\right)$. We also consider an alternative, text-based measure of exposure to Brexit. Under this approach, 807 firms are assigned to the treated category (2015 10-K mentions of Brexit terms > 5). A total of 433 firms in the control category have no mentions of Brexit-related terms in their 10-Ks.

\subsubsection{Timeline}

Once firms are identified as exposed and non-exposed, we need to set the time-frame of our DID analysis. We make this determination by mapping key events of our institutional setting into market-based measures of perceived uncertainty. In Figure 3, we plot three point-in-time snapshots of the term structure of implied volatility for the FTSE100 Index. The dynamics described in this figure help us identify dates in which uncertainty surrounding the Brexit referendum seems to be incorporated into market expectations. ${ }^{19}$

\footnotetext{
${ }^{18}$ In unreported tests, we only label those firms with statistically significant positive $\beta_{i}^{U K}$ estimates as treated firms, and those with $\beta_{i}^{U K}$ statistically indistinguishable from zero as controls. We find that our results hold across a range of sensible treatment assignment thresholds.

${ }^{19}$ The implied volatility term structure serves as a metric of market uncertainty over time as it expresses the range of movements in the FTSE100 that investors expect over various horizons (see Dumas et al. (1998) and Mixon (2007)). The values in Figure 3 reflect the market's expectation of the volatility of the FTSE100 over different maturities. For example, if annualized implied volatility for 2 years is $15 \%$, the market expects that prices will move over the next 2 years within a band $[-(15 \times \sqrt{2} \%),+(15 \times \sqrt{2}) \%]$ with $68 \%$ probability (one standard deviation).
} 


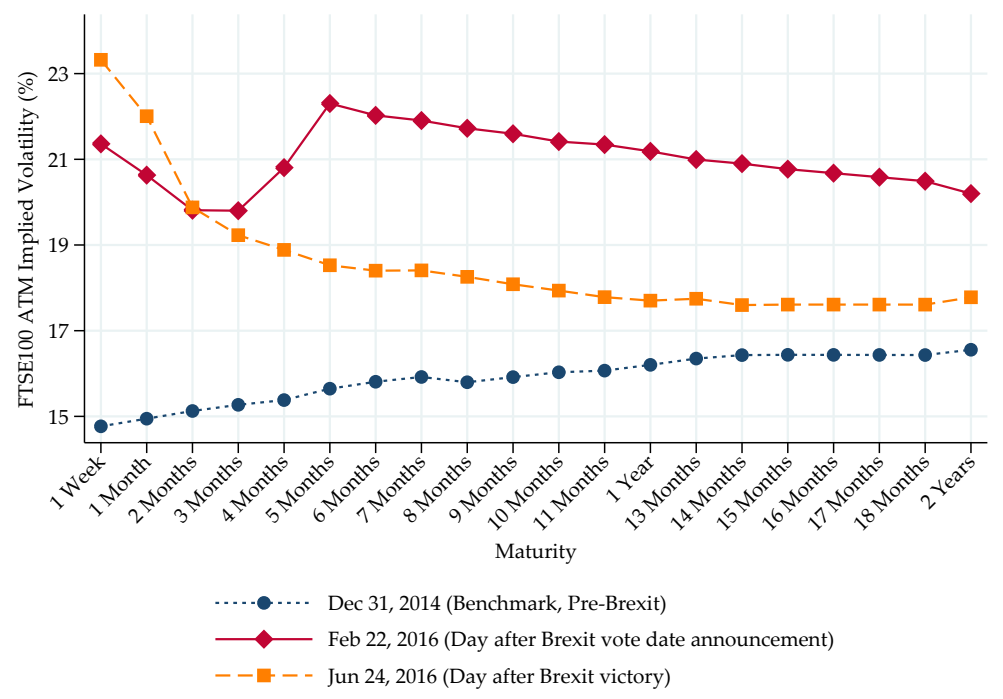

Figure 3. Term Structure of FTSE100 Implied Volatility. This figure shows the term structure of the FTSE100 Index at three different dates. The term structure at each date is constructed from average Black-Scholes implied volatilities derived from quoted prices of at-the-money options on the FTSE100 Index. The values plotted reflect the market's expectation of the volatility of the FTSE100 index over various maturities considered.

The first (dotted blue) curve in Figure 3 represents the term structure as of December 31, 2014, which is the last date of our $\beta_{i}^{U K}$ estimation period. We use this curve as a benchmark since expectations at that time were uncontaminated by Brexit. As is typical for equities during normal economic conditions, the term structure is upward sloping, indicating the market expects greater volatility at longer horizons. The curve hovers smoothly around the 15-16\% range, suggesting that no abrupt changes are expected by options market participants over a maturity horizon of up to two years.

Responses to official news about the exact referendum date suggest that market participants were quick to incorporate uncertainty embedded by Brexit in their trading activity — before the actual outcome of the vote. In particular, options trading taking place on February 22, 2016 (continuous red curve in Figure 3), the first trading day following David Cameron's announcement of the Brexit vote date, were priced to reflect a significant drop in market volatility for the period leading up to the Brexit vote date (on June 23), only to show a spike in volatility right after the vote. On June 24, 2016 (dashed yellow curve), the first trading day following the vote, market uncertainty seemed unusually high. Resolution about the vote outcome, nonetheless, seems to quell uncertainty forecasts. In particular, the one-year ahead implied volatility immediately after the vote date is not significantly different from that registered back in December 2014.

Having examined market uncertainty in the UK based upon implied options volatility, we set out to verify in our US firm-level data if this period coincided with increased perceived income uncertainty for High UK-Exposure firms. We do so using data on analysts' forecasts from the I/B/E/S database. Beginning in 


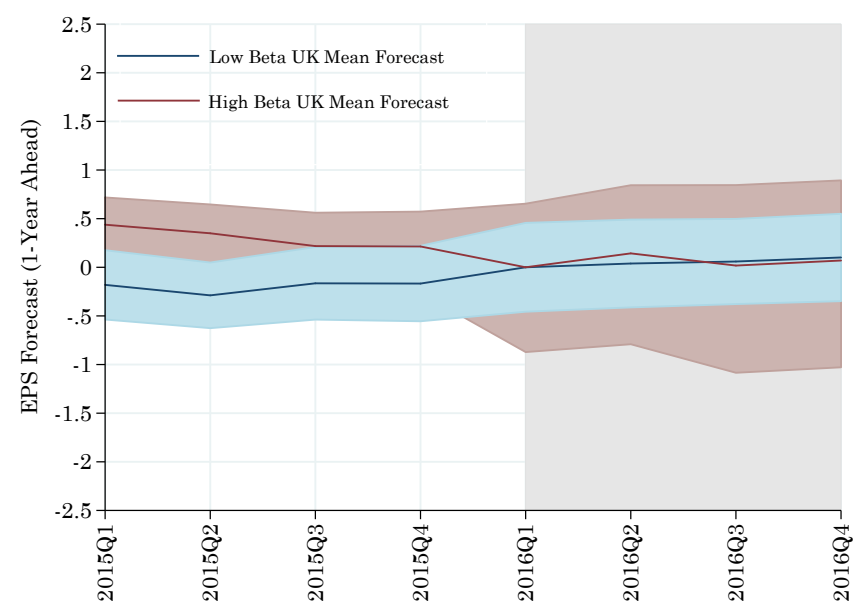

Figure 4. Analysts' Earnings Per Share Forecasts around Brexit. This figure shows how analyst Earnings Per Share (EPS) forecasts behaved around Brexit's key dates. Confidence intervals are calculated as \pm 1.5 standard deviations from the mean forecast. Each line represents a group of firms sorted by exposure to the UK economy as measured by $\beta_{i}^{U K}$. The shaded area marks the beginning of Brexit-related events with the announcement of the date of the UK-EU referendum by PM David Cameron (2016:Q1). Both series are normalized to take the value of 0 in 2016:Q1.

2015:Q1, we obtain the 1-year ahead earnings per share (EPS) forecasts for each firm in our sample and compute the mean and standard deviation of forecasts. We quantify earnings forecast uncertainty for firms in the high and low $\beta_{i}^{U K}$ groups by constructing \pm 1.5 standard-deviation intervals around their group mean forecasts in Figure 4. The figure shows no discernible difference in mean forecasted earnings between high and low $\beta_{i}^{U K}$ firms, suggesting analysts did not expect UK-exposed firms to do any worse, on average, in terms of earnings performance following the Brexit vote. ${ }^{20}$ The fact that mean EPS forecasts stay virtually the same over the 2-year window for both high and low $\beta_{i}^{U K}$ firms suggests that there is no clear sign of a "first-moment" (negative) effect of Brexit on US corporate earnings. That same earnings forecasts evidence points to the Brexit vote having a "second-moment" effect in terms of increased uncertainty regarding UKexposed firms' expectations in 2016:Q1-Q2. In particular, EPS forecast dispersion of High UK-Exposure firms increases significantly in early 2016.

In our empirical tests, we compare two quarters before versus two quarters after the two key Brexit events we have just identified (February 22 and June 23, 2016). We focus on a relatively short window around the Brexit vote as Bloom (2009) highlights the sharp yet short-lived nature of the economic effects triggered by

\footnotetext{
${ }^{20}$ In formal tests, we confirm that the differences in consensus EPS forecasts between high and low $\beta_{i}^{U K}$ firms are not statistically significant in the pre-Brexit vote period.
} 
uncertainty. ${ }^{21}$ We limit our analysis to the end of 2016 due to the start of the Trump administration in January 2017. We show in later robustness checks that results also hold for a window that excludes Trump's election.

\subsubsection{Empirical Model}

We compare differences in outcomes of interest between treated (High UK-Exposure) and control (Low UKExposure) firms. Differences over the 2016:Q3-Q4 period are taken relative to the same two quarters in the previous year, 2015:Q3-Q4, in order to minimize the impact of seasonal effects. This is equivalent to estimating the following model:

$$
\begin{aligned}
Y_{i, t}= & \alpha+\delta\left[\text { Post }_{t} \times\right. \text { High UK-Exposure } \\
& \\
& +\theta \text { Controls }_{i, t-1}+\sum_{i} \text { Firm }_{i}+\sum_{j} \sum_{t}\left[\text { Industr } y_{j} \times \text { Quarter }_{t}\right]+\epsilon_{i, t}
\end{aligned}
$$

The outcomes of interest, $Y_{i, t}$, are fixed capital investment, employment growth, R\&D expenditures, divestitures, cash holdings, and non-cash working capital. High UK-Exposure $e_{i}$ is a dummy variable that equals 1 if firm $i$ is UK-exposed and zero otherwise. A firm is considered to be UK-exposed according to two measures: (1) if it belongs to the top tercile of $\beta_{i}^{U K}$ (market-based measure); or (2) if it has a high number of Brexitrelated entries in its 2015 10-K form (textual-search-based measure). Post $t_{t}$ equals 1 if the time period is in the 2016:Q3-Q4 window.

Controls $_{i, t-1}$ is a vector of macroeconomic and firm-level control variables. Macro controls include the lagged US dollar/British pound FX rate, the lagged VIX implied volatility index, the lagged mean GDP growth 1-year-ahead forecast from the Federal Reserve Bank of Philadelphia's Livingstone Survey, the lagged Consumer Sentiment Index from the University of Michigan, and the lagged Leading Economic Indicator from the Federal Reserve Bank of Philadelphia. Firm-level controls include lagged stock returns, Tobin’s $Q$, cash flow, logged assets, and sales growth. As an additional control for first-moment effects of Brexit, we add 1quarter-ahead consensus earnings forecasts to our model. Firm ${ }_{i}$ represents firm-fixed effects, Industry is a dummy for each industry category $j$ of the Hoberg and Phillips (2016) classification (FIC 100), ${ }^{22}$ and Quarter $_{t}$ are calendar-quarter dummies. Standard errors are double-clustered by firm and calendar quarters.

\footnotetext{
${ }^{21}$ Figure C.1 in Appendix C shows differences in investment trends between treated and control firms in the window surrounding the vote. Brexit-induced uncertainty led to a significant, yet temporary, drop in investment for affected US firms for a period of three quarters, followed by a rebound to near normalcy in the following three quarters. This "drop-and-rebound" behavior matches the pattern of domestic uncertainty shocks discussed in Bloom (2009).

${ }^{22}$ These industries are formed by grouping firms with textually similar product descriptions in their 10-Ks. Hoberg and Phillips (2016) show that the resulting industry classification is more granular and captures the locus of productmarket competitors of a given firm better than the standard SIC or NAICS industry schemes.
} 


\subsection{Descriptive Statistics}

Table 1 presents our sample summary statistics. Firm-level accounting variables are normalized by lagged total assets. We begin with Panel A presenting the statistics for the universe of COMPUSTAT firms in the pre-Brexit sample period (2010:Q1-2015:Q4). Using our baseline market-based $\beta_{i}^{U K}$ criterion, Panel B summarizes the data for treated firms as defined by $\beta_{i}^{U K}$ (those in the top tercile of $\beta_{i}^{U K}$ ), while Panel C reports statistics for control firms as defined by $\beta_{i}^{U K}$ (bottom tercile of $\beta_{i}^{U K}$ ). Panels D and E report summary statistics for treatment and control firms, respectively, as defined by mentions of Brexit-related words in firms' 10-K filings (our text-based approach).

\section{TABLE 1 ABOUT HERE}

The reported statistics show that our sample firms do not display salient discrepancies relative to the universe of COMPUSTAT firms. Comparisons across subsamples suggest that treated and control firms (as defined by $\beta_{i}^{U K}$ ) differ across a few characteristics: firms in the treatment group are smaller as measured by total assets and invest more than control firms. However, firms in the treated group as defined by $10-\mathrm{K}$ mentions of Brexit-related words are, if anything, larger than those in the control group, while their investment appears to be similar. Treatment and control firms share similarities on a number of dimensions across both assignment schemes we use. They display economically similar R\&D expenditures, cash holdings, Tobin's Q, and employment growth. To ensure that differences in firm characteristics do not drive our results, we redo all of our tests on propensity-score matched samples in which firm-level characteristics are balanced before any estimations are conducted. Table C.2 displays summary statistics of the matched samples. Table C.3 reports the results of our main estimations on these matched samples. To further verify that treated and control firms are not fundamentally different, we examine the validity of the parallel trends assumption. Visual evidence for that assumption regarding the investment process is provided in Figure C.1. Tables C.4 and C.5 report formal tests supporting the presence of parallel trends across all outcome variables. 


\section{Results}

\subsection{The Impact of the Brexit Vote on US Firms' Investment, Labor, R\&D, and}

\section{Divestitures}

Results from our baseline estimations for investment and employment are shown in Table 2. We begin with a firm-fixed effects estimation in which $\beta_{i}^{U K}$ enters the specification as a linear continuous-treatment variable in column (1), allowing for the entire range of $\beta_{i}^{U K}$ values. The Post $\times \beta_{i}^{U K}$ interaction coefficient is negative and highly significant, consistent with Prediction 1. In short, it points to the interpretation that a higher exposure to the UK is linked to lower investment spending following the 2016 Brexit vote. We move to our baseline specification in column (2), which considers the non-negative range of $\beta_{i}^{U K}$ partitioned in terciles. The model includes time-varying industry-fixed effects by way of interacting Hoberg and Phillips (2016) industries (FIC 100) and calendar-quarter dummy variables. The Post $\times$ High $\beta_{i}^{U K}$ coefficient is again negative and statistically significant. Finally, we consider our text-based approach to measure firmlevel exposure to the UK in column (3). The Post $\times$ High 10-K Entries DID coefficient is once again negative. The investment reductions reported in all of these estimations are not only statistically, but also economically significant. Given that the pre-Brexit (2015) average investment was $1.1 \%$ of firms' assets, the DID estimate of -0.165 implies a drop of up to $15 \%$ in investment rates. As a first-order approximation, the dollar magnitude of aggregate investment cuts implied by this estimate is around $\$ 2$ billion. ${ }^{23}$ Estimates under columns (1) through (3) show that following the Brexit vote victory, UK-exposed American firms significantly cut their investment vis-à-vis non-UK-exposed counterparts. ${ }^{24}$

\section{TABLE 2 ABOUT HERE}

The impact of the Brexit vote on corporate employment is also reported in Table 2. Using the specifications previously adopted, columns from (4) through (6) display negative and significant DID coefficients for employment growth. The estimated coefficients imply a drop of between 2.6 and 4.9 percentage points. Given that pre-Brexit (2015) sample average employment growth was 3.4\%, our results suggest that the Brexit

\footnotetext{
${ }^{23}$ The 449 firms in the top tercile of $\beta_{i}^{U K}$ had average assets of $\$ 2.81$ billion in 2016:Q2. A decline in their investmentto-assets ratio of 0.165 percentage points implies a drop in investment of $\$ 4.64$ million per firm, or $\$ 2.08$ billion in total.

${ }^{24}$ In Table C.7, we show that our baseline findings are robust to the inclusion of numerous controls for simultaneous changes in the first-moment component of the Brexit shock. These include Tobin's Q, Cash Flow, Sales Growth, Consensus Earnings Forecasts, and one-year Stock Returns. Additionally, we include the firm-level first-moment instruments for the USD-GBP exchange rate, the price of oil, and the Treasury rate from Alfaro et al. (2018). These variables jointly serve as proxies for changes in firms' expected profitability coinciding with the Brexit vote.
} 
vote contributed to a measurable slowdown in net job creation in some segments of the US economy, with the upper bound estimate pointing to a reduction in employment for UK-exposed firms. This is a notable finding given the steady growth in employment observed across the US since 2010, particularly during 2016.

Next, we study the effects of the Brexit vote on UK-exposed firms' innovation policies. Columns (1) through (3) of Table 3 show that, for all specifications of UK-exposure, there is a positive and highly significant response of $R \& D$ spending to Brexit. This result is consistent with the growth-options channel discussed in our theoretical framework. The results for R\&D are also economically significant, reaching an increase of 0.24 percentage points relative to the pre-Brexit average of $3.2 \%$ of assets.

\section{$\overline{\text { TABLE } 3 \text { ABOUT HERE }}$}

Finally, we look into the effects of the Brexit vote on UK-exposed firms' disinvestment (the sales of plant, property and equipment scaled by lagged total assets). Columns (4) through (6) of Table 3 suggest that Brexit led to substantial reductions in divestitures for UK-exposed firms. The magnitudes here are notable, with a decline of up to 0.03 percentage points, representing $33 \%$ of the average divestiture rate of the pre-Brexit period. Confirming the predictions of our framework, Brexit-induced uncertainty led to a reduction in both capital investment and disinvestment by affected US firms.

\subsection{Result Characterization}

\subsubsection{Tracing Investment and Labor Cuts}

Since we are looking at multinational firms, it is important that we identify whether investment and job reductions occur within US borders or stem from cuts in foreign operations. In this section, we first investigate whether investment cuts observed amongst American firms exposed to the UK affected operations that take place in the United States. We then look at the location of jobs affected by the Brexit vote. We also study the types of US jobs and workers affected by the 2016 British vote.

\section{The Location of Investment Cuts}

We determine the location of investment cuts using data from Orbis. With these data, we are able to conduct our baseline analysis on investment looking squarely at US-based operations of companies domiciled in the United States. The total number of US-based subsidiaries in our sample is 51,750. For each parent 
firm, in each year, we compute their US-based investment by summing fixed capital spending across their US subsidiaries. We then repeat the analysis of Table 2 using US-based investment as the dependent variable. Results in columns (1) and (2) of Table 4 indicate that UK-exposed American firms cut investment in their US-located subsidiaries in response to the Brexit vote. The magnitudes of the investment cuts are larger than those reported in Table 2 (annualized), implying that effects on investment measured at the parent firm level are driven in large part by investment cuts in their US operations.

\section{TABLE 4 ABOUT HERE}

As a further check, we investigate whether these UK-exposed American firms cut investment in their UK-based subsidiaries as well. Using Orbis, we identify UK subsidiaries of our US-domiciled firms. We similarly calculate the total UK-based investment of each US parent firm by summing spending figures across UK subsidiaries. We then repeat our baseline analysis with this measure of UK investment as the dependent variable. Results in columns (3) and (4) of Table 4 suggest that UK-exposed American firms cut investment in their UK-based subsidiaries even more than they do across their US-based subsidiaries. This result is sensible and consistent with a strong, direct effect of Brexit-induced uncertainty on UK-based operations.

\section{The Location and Nature of Employment Cuts and Establishment Turnover}

We are able to identify the location of employment cuts made by American firms using the YTS database. We first repeat the analysis of Table 2 using establishment-level employment growth calculated based on YTS data on the number of employees across all establishments operated by sample firms in the US. Results in columns (1) and (2) of Table 5 suggest that UK-exposed American firms reduced their employment in the US following the Brexit vote. The magnitude of the employment cuts reported in columns (1) and (2) of Table 5 are larger than those reported in columns (5) and (6) of Table 2, suggesting that effects on employment measured at the aggregate US-domiciled firm level are likely to be driven by employment declines in their US-based operations. Relatedly, real options theory predicts an increase in the option value of "wait and see" in response to uncertainty. We thus analyze if Brexit affected exposed firms' decisions on opening and closing establishments in the US, which we define as establishment turnover. ${ }^{25}$ Columns (3) and (4) display negative and significant coefficients, suggesting that UK-exposed firms indeed reduce their establishment turnover and confirms our predictions about firm inaction.

\footnotetext{
${ }^{25}$ Establishment turnover is defined as the sum of establishment openings and closings, divided by the lagged number of total establishments.
} 


\section{TABLE 5 ABOUT HERE}

We delve into the nature of employment cuts by considering whether the reductions in employment following the Brexit vote were felt primarily among the higher or lower skilled workforce. As a proxy for labor skills, we use the industry-level labor skill index (LSI) proposed by Ghaly et al. (2017). The LSI is based on data from the Occupational Employment Statistics (OES) compiled by the BLS and the Department of Labor's O*NET program classification. The O*NET classification allocates occupations into five categories where scores of 1 (5) correspond to the lowest (highest) skilled occupations, based on the extent of education, experience, and training required to perform each occupation. An industry's LSI is computed as the weighted average $\mathrm{O}^{*} \mathrm{NET}$ classification across all occupations in that industry, where the weights correspond to the fraction of workers engaged in each occupation.

Columns (5) through (8) of Table 5 report results on the effect of the Brexit vote on employment growth in subsamples of firms partitioned into two groups based on the 2015 (pre-Brexit) LSI. Firms in the Low Skill subsample are in industries which fall within the lowest tercile of LSI and firms in the High Skill subsample are in industries which fall within the highest tercile of LSI. The results in columns (5) and (6) show that UK-exposed American firms in Low Skill industries (including food, chemical, and primary metal manufacturing, mining, and clothing retail) cut their employment substantially more (relative to control firms). Conversely, the estimates in columns (7) and (8) indicate that firms in High Skill industries (computer and electronic product manufacturing, telecommunications and information services and professional, technical and scientific services) show no statistically significant effect.

\subsubsection{Input versus Output Channels}

We next study whether the effect of UK-based uncertainty on US corporate investment was driven by firms that were importers from the UK or exporters to the UK. We do this using the index of firms' offshoring activities developed by Hoberg and Moon (2017). This index, derived from firms' 10-K filings, counts mentions of words related to the purchase of inputs ("Input") and sale of outputs ("Output”) from each country a firm does business with within a year. For each sample firm, we compute the sum of the Input and Output indices associated with the UK over the 2010-2014 period (similar to our $\beta_{i}^{U K}$ estimation window). We consider each of the Input and Output indices separately, as well as combined (Total). We define as highly 
UK-offshoring-exposed firms those with a value of greater than five on a given offshoring index. ${ }^{26}$ Control firms are those with scores of zero on the same index.

\section{TABLE 6 ABOUT HERE}

The first two columns of Table 6 report our baseline results on the effects of the Brexit vote on investment for ease of comparison, while the next three columns report analogous results for treatment schemes based on offshoring activities to the UK. The estimate in column (3) indicates that US firms with a high degree of total offshoring activity with the UK significantly cut their investment relative to US firms with no UK offshoring. The magnitude of this effect is remarkably similar to those of our base tests. In columns (4) and (5), we consider Input and Output indices separately. This more detailed analysis is important in revealing that the aggregate cut in investment that we identified was driven by firms with high Input exposure to the UK. A closer examination of disclosure data reveals that these firms have more operations in the UK (e.g., manufacturing units), utilizing labor, capital, and raw material inputs from the UK. The effect on the investment of US firms with high Output exposure to the UK is zero. These results suggest that input-based economic links play a crucial role in the cross-country transmission of uncertainty and its effects on corporate investment and hiring decisions.

\subsubsection{The Effect of Input Irreversibility}

We turn to the analysis of adjustment costs in modulating the effect of uncertainty on investment and employment as a way to more finely characterize our results (cf. Predictions 4 and 5). We begin by looking at fixed capital adjustment costs. We do so introducing a firm-level proxy for capital investment reversibility; namely, the Kim and Kung (2016) asset redeployability index. Columns (1) through (3) of Table 7 show results on the amplification effect of capital adjustment costs. In column (1), we run the DID estimation that considers firms in the top tercile of $\beta_{i}^{U K}$ as the treatment group. In this first run, we restrict the sample to firms with high irreversibility, as defined by the bottom tercile of the Kim and Kung index. The DID coefficient is negative and highly significant. The same exercise is repeated in column (2), but for the subsample of firms in the top tercile of asset redeployability; that is, firms with plausibly less irreversible investment.

\footnotetext{
${ }^{26}$ While this threshold is arbitrary and meant to follow our previous approach to textual-search-based measurement of exposure to the UK, our findings are robust to alternative choices. The sample size in columns (3) through (5) are enlarged due to greater coverage of the Hoberg and Moon (2017) offshoring data. We confirm that the findings hold in the subsample comprising the intersection of our baseline sample (in columns (1) and (2)) with the Hoberg and Moon (2017) offshoring data.
} 
The DID coefficient is insignificant for this group of firms. The estimation under column (3) uses the entire sample of firms, introducing a dummy variable High Irreversibility that equals one if the firm is in the high irreversibility group. The coefficient on this variable can be interpreted as a third difference in a differencestest framework; that is, as a DIDID estimate. The coefficient for the triple interaction in column (3) is negative and highly significant, implying that cross-group responses are economically and statistically distinct, in line with Prediction 4.

\section{$\overline{\text { TABLE } 7 \text { ABOUT HERE }}$}

We next turn to the impact of labor adjustment costs, using industry-level unionization rates as a proxy for such costs. Columns (4) through (6) of Table 7 show that the response of firms in more unionized industries is significantly different from that of firms in less unionized industries. ${ }^{27}$ This analysis suggests that the effect of uncertainty on US corporate employment following the 2016 Brexit vote was modulated by input irreversibility, as implied by Prediction 5. In all, the results of Table 7 confirm the theoretical prior that capital and labor adjustment costs significantly affected US firms' responses to Brexit-induced uncertainty.

\subsection{Other Firm Policies and Outcomes}

We also study how the 2016 Brexit vote affected other firms' policies, especially their liquidity management. We do so looking at how firms adjusted their cash holdings and non-cash working capital (NWC). The positive and highly significant coefficients in columns (1) and (2) in Table 8 show that UK-exposed firms increased their cash savings in the face of higher uncertainty induced by the Brexit vote. Negative and highly significant coefficients in columns (3) and (4) show that firms concomitantly accumulated less inventory by adjusting their NWC downwards. Although not explicitly modeled in our framework, this behavior is consistent with the theoretical underpinnings from the liquidity management literature. In particular, precautionary behavior will lead firms to change the composition of assets on their balance sheets, leading to the accumulation of the most liquid assets.

\section{TABLE 8 ABOUT HERE}

We further use Table 8 to report results on profit growth. The estimates in columns (5) and (6) are not statistically significant, suggesting that the Brexit vote did not affect the profitability of UK-exposed American

\footnotetext{
${ }^{27}$ The pooled sample in column (6) has significantly fewer observations than that in column (3) owing to the fact that investment is reported quarterly while employment is reported annually in COMPUSTAT.
} 
firms relative to those of non-exposed firms. They support the idea that the investment and employment drops previously reported are arguably due to a "second-moment" shock to income uncertainty, rather than a negative "first-moment" shock to firms' cash flows.

\section{Robustness}

\subsection{Foreign Exchange Exposure}

The Brexit vote was followed by a depreciation of the British pound (9\% relative to the US dollar). To the extent that our treatment assignment schemes may be correlated with firms' exposures to US dollar/British pound (henceforth, USD-GBP) fluctuations, our results could reflect UK-exposed firms' heterogeneous responses to the British pound depreciation (affecting first-moment expectations) rather than to uncertainty generated by the Brexit vote (second-moment expectations). In what follows, we account for this possibility by controlling for firms' exposures to FX rate fluctuations in the value of the British pound.

First, we estimate a dynamic analogue of Eq. (13), firm-by-firm, over our testing period. ${ }^{28}$ Instead of regressing the volatility of firm equity returns on the volatilities of US and UK equity index returns and the volatility of changes in the USD-GBP FX rate, we regress the levels of firms' equity returns on the levels of US and UK equity index returns and USD-GBP FX rate changes. This specification aims at capturing the firstmoment exposures of firms to movements in the pound. We include as an additional control each firm's

end-of-quarter coefficient on $F X^{\$ / \varepsilon}$, namely $\beta_{i, t}^{F X^{\$ / \varepsilon}}$, which captures the time-varying sensitivity of firm $i$ 's equity returns to changes in the British pound. Second, we include in our estimations the Alfaro et al. (2018) firm-level instruments for first- and second-moment shocks to the USD-GBP rate. Our final two controls are based on firm disclosures of hedging activities. Following Campello et al. (2011), we search for mentions of keywords that are meant to capture FX hedging activity in 10-K disclosures. We include as additional controls a dummy variable for whether a firm engaged in FX hedging activity in the prior year, and the intensity of hedging in the prior year as measured by the number of keywords mentioned.

\section{$\overline{\text { TABLE } 9 \text { ABOUT HERE }}$}

Results in Table 9 indicate that our inferences on firm responses to the Brexit vote continue to hold even in the presence of various controls for their possible heterogeneous exposures to the depreciation of the

\footnotetext{
${ }^{28}$ Specifically, we perform our estimation using monthly returns data, with 24 -month rolling windows, over the period 2010:M1 through 2016:M12.
} 
British pound. Results in columns (1) and (2), for instance, show estimated DID coefficients of between -0.08 and -0.17 , which are virtually identical to those in columns (2) and (3) of Table 2. The results suggest that the observed investment cuts are unlikely to be confounded by firms reacting to changes in first-moment expectations arising from the British pound depreciation that followed the Brexit vote.

\subsection{Financing Costs}

We next investigate whether any of the effects we observe may be ascribed to UK-exposed firms experiencing higher financing costs as a result of heightened uncertainty induced by the Brexit vote. Prior research has shown that periods of higher uncertainty are associated with increased credit spreads, which may lead firms to curtail investment (Gilchrist et al. (2014)). We accommodate for this channel in our analysis by accounting for several proxies of firms' ability to raise financing in the debt and equity markets following the Brexit vote. In particular, we re-estimate the analysis of Table 2 controlling for yields on existing bonds (obtained from TRACE), yields on new bond issues (from SDC), mark-ups on new syndicated loans (from DealScan), and for the discount rate news component of returns (from the decomposition of returns news into cash flow news and discount rate news components as in Vuolteenaho (2002)).

\section{$\overline{\text { TABLE } 10 \text { ABOUT HERE }}$}

Results in Table 10 indicate that our findings continue to obtain when accounting for possible tightening of firms' financing costs. For instance, results in columns (1) and (2) produce DID coefficients ranging between -0.07 and -0.17 , which closely resemble those in columns (2) and (3) of Table 2. Our evidence suggests that observed investment cuts are driven primarily by the real-options channel, and are not subsumed by firms' financing costs.

\subsection{Exposure to Automation Technology}

An alternative channel that could explain our investment, employment, and R\&D results is firms' concurrent adoption of automation technologies. Firms implementing a more automated production process may experience higher innovation spending related to building technologies that replace employees and reduce

the dependence on fixed assets. We test for this channel using two different approaches. First, borrowing from Acemoglu and Restrepo (2020), we adopt a geographic perspective on the exposure to automation. Those authors rely on data compiled by Leigh and Kraft (2018), who scrape the web to obtain the location 
and employment of robot integrators - companies that install, program, and maintain robots. Using these novel data, Acemoglu and Restrepo (2020) construct estimates of robot integrator activity in all commuting zones (CZ) of the continental United States. ${ }^{29}$ We define our first, geography-based variable capturing firms' exposure to automation technologies, Automation \{ $i \in C Z\}_{\text {, }}$, by matching each firm $i$ in our sample to a CZ (based on the firm's headquarters location).

Second, going beyond geographical exposure, we construct a more granular, firm-level measure of exposure to automation borrowing from the textual analysis literature in corporate finance (e.g., Loughran and McDonald (2011)). ${ }^{30}$ We define Automation $_{i}$ as a continuous variable that measures how frequently the top 100 automation keywords appear in each firm's business description (10-K Section 1) and management discussion (10-K Section 7). To capture cases in which a firm discusses automation efforts in only one year, we average the word count across the pre-Brexit years in our sample (2010-2015).

\section{$\overline{\text { TABLE } 11 \text { ABOUT HERE }}$}

Table 11 shows our baseline DID specifications augmented with both controls for exposure to automation. Our coefficients of interest remain statistically significant, suggesting that our results are robust to accounting for the automation technology channel.

\subsection{Accounting for Trump's Election}

One could be concerned about confounding uncertainty effects associated with the election of President Donald Trump in the United States. We address this issue in two different ways. First, we consider an alternative event window that excludes 2016:Q4 from our treatment evaluation period. This narrower time window helps mitigate concerns that forward-looking behavior of firms regarding Trump's election in the US could influence our results (Trump's victory was an unlikely event as of 2016:Q3). Accordingly, we compare the third quarter of 2016 with the same quarter of 2015. As shown in columns (1) and (2) of Table 12, results are similar to our baseline estimates in Table 2 . The patterns we report are consistent with relatively short-lived, "drop-and-rebound" effects of uncertainty.

\footnotetext{
${ }^{29}$ For a map of the CZ-level exposure measure, see Acemoglu and Restrepo's (2020) Figure 4, Panel A.

${ }^{30} \mathrm{To}$ do so, we define a dictionary of keywords that capture automation at the firm level. We first gather the syllabuses of many courses on "Industrial Automation and Integration" taught at top Engineering schools. We then read each syllabus to identify the most frequently adopted textbook. This analysis points to Benhabib’s (2003) "Manufacturing: Design, Production, Automation, and Integration" as one of the most commonly required textbooks. We parse the full text content of the textbook for the 100 most distinctive keywords related to automation (based on the TextRank algorithm, see Mihalcea and Tarau (2004)) and use them as a dictionary for parsing firms' 10-Ks. In Appendix E, we detail the construction of the firm-level automation exposure variable and plot its distribution.
} 


\section{$\overline{\text { TABLE } 12 \text { ABOUT HERE }}$}

Second, we look at the recent literature on the effect of Trump's election on US firms. Wagner et al. (2018) detail a methodology identifying what the authors label as "winners" and "losers" from that election. We use their method, which is based on 10-day cumulative CAPM-adjusted abnormal stock returns around the Trump election date, to check for the presence of either of these sets of firms in our sample. Our treatment group based on $\beta_{i}^{U K}$ (10-K mentions) contains 57 (23) "loser" firms. In columns (3) and (4) of Table 12, we replicate our baseline tests on investment omitting firms labeled as "losers" by Wagner et al. (2018); that is, firms that might invest less because of Trump's election. The estimates show that our inferences are unaffected by these firms. ${ }^{31}$

\subsection{Falsification Tests}

We also address concerns that our test design is set up in a way that may generate results not necessarily tied to the June 2016 referendum result. In doing so, we re-estimate our tests considering two "treatment periods" that occurred prior to the 2016 Brexit vote: (1) David Cameron's election as Prime Minister (2015:Q3); and (2) the US Debt Ceiling Crisis of 2011 (2011:Q2-2011:Q4). The first falsification test mitigates concerns that firms anticipated the process leading to the Brexit referendum at the time of Cameron's election. The second addresses concerns that our investment results could be driven by episodes of uncertainty in the US — and not the UK — that affect global firms in general. As shown in columns (5) through (8) of Table 12, the DID coefficients are statistically insignificant in all such cases.

\subsection{Uncertainty in the Global Economy}

We conduct a battery of supplementary tests to rule out the possibility that our results on investment cuts in the US may be driven by coincident, potentially uncertainty-inducing events that take place in economies other than the UK. To do so, we construct metrics analogous to our baseline UK-exposure measure, $\beta_{i}^{U K}$, by re-estimating Eq. (13) for developed and emerging markets with relevant trade ties to the US: EU, China, Mexico, Japan, India, and Brazil. In other words, we repeat our tests classifying firms based on a given criterion $-\beta_{i}^{E U}, \beta_{i}^{\text {China }}, \beta_{i}^{\text {Mexico }}, \beta_{i}^{\text {Japan }}, \beta_{i}^{\text {India }}$, and $\beta_{i}^{\text {Brazil }}-$ according to the sensitivity of their equity returns volatility to the respective region's main equity index return volatility. In this estimation, performed

\footnotetext{
${ }^{31}$ For completeness, we repeat our analysis also excluding "winner" firms and find no changes in our results.
} 
over the same pre-Brexit sample period of 2010:M1 through 2014:M12, we control for the FTSE100 volatility, the US dollar/British pound exchange rate volatility, and the volatility in the exchange rate of the US dollar and the currency of each country.

\section{$\overline{\text { TABLE } 13 \text { ABOUT HERE }}$}

Results are reported in Table 13. Column (1) repeats our baseline estimate from Table 2 to ease comparisons. In column (2), we find that American firms exposed to EU uncertainty also experienced significant

investment declines. The much smaller $\beta_{i}^{E U}$ estimate is sensible and consistent with the fact that Brexitrelated events induced political uncertainty in the EU as well as the UK. Results in columns (3) through (6) show that US firms exposed to uncertainty in several other economies experienced no significant change in their investments in the quarters following the announcement of the Brexit referendum. Our main results are unlikely to be driven by American firms' exposures to events other than the 2016 Brexit vote in the UK.

\section{Concluding Remarks}

Political uncertainty appears to be a growing phenomenon, seemingly fueled by populism and a rejection of institutions associated with international finance, migration, and trade. This dynamic seems to be economically important, yet our understanding of its consequences is limited. In this paper, we provide firm-level evidence of transmission of uncertainty generated by the 2016 Brexit referendum onto American corporations. Our analysis shows how US firms that were exposed to the UK economy changed a myriad of business policies — including their investment, disinvestment, hiring, R\&D, and savings — in response to 2016 Brexit vote. As the British anti-integration referendum has reportedly inspired similar national-centric movements in other countries, it is important that researchers and policy makers are able to gauge its larger implications.

Our results show how foreign-born uncertainty is transmitted across borders, shaping domestic capital formation and labor allocation. Yet, the effects we identify on UK-exposed firms in the US are likely only a few of the many channels through which economic uncertainty is transmitted across borders. One must bear in mind that the 2016 Brexit referendum set in motion a complex process that is bound to last for several years and affect many other countries connected through the global economy. One of the important aspects of our analysis is shedding light on the fact that politicians and regulators can affect the economy not only through policies they enact, but also by introducing uncertainty in the process of making decisions. Such uncertainty has real and financial consequences not only for the country that originates it, but for other countries as well. 


\section{References}

Acemoglu, Daron, and Pascual Restrepo, 2020, Robots and jobs: Evidence from US labor markets, Journal of Political Economy 128, 2188-2244.

Acharya, Viral V., Heitor Almeida, and Murillo Campello, 2013, Aggregate risk and the choice between cash and lines of credit, Journal of Finance 68, 2059-2116.

Alfaro, Ivan, Nicholas Bloom, and Xiaoji Lin, 2018, The finance uncertainty multiplier, National Bureau of Economic Research, Working Paper n. 24571.

Azzimonti, Marina, 2016, Does partisan conflict deter FDI inflows to the US?, National Bureau of Economic Research, Working Paper n. 22336.

Baker, Scott R., Nicholas Bloom, and Steven J. Davis, 2016, Measuring economic policy uncertainty, Quarterly Journal of Economics 131, 1593-1636.

Bar-Ilan, Avner, and William Strange, 1996, Investment lags, The American Economic Review 86, 610-622.

Bar-Ilan, Avner, and William Strange, 1998, A model of sequential investment, Journal of Economic Dynamics and Control 22, 437-463.

Becker, Sascha O., Thiemo Fetzer, and Dennis Novy, 2017, Who voted for Brexit? A comprehensive districtlevel analysis, Economic Policy 32, 601-650.

Benhabib, Beno, 2003, Manufacturing: Design, production, automation, and integration (CRC Press).

Berg, Tobias, Anthony Saunders, Larissa Schäfer, and Sascha Steffen, 2019, Brexit and the contraction of syndicated lending, Working Paper.

Bernal, Oscar, Jean-Yves Gnabo, and Grégory Guilmin, 2016, Economic policy uncertainty and risk spillovers in the Eurozone, Journal of International Money and Finance 65, 24-45.

Bloom, Nicholas, 2009, The impact of uncertainty shocks, Econometrica 77, 623-685.

Bloom, Nicholas, 2014, Fluctuations in uncertainty, Journal of Economic Perspectives 28, 153-175.

Bloom, Nicholas, Max Floetotto, Nir Jaimovich, Itay Saporta-Eksten, and Stephen J. Terry, 2018, Really uncertain business cycles, Econometrica 86, 1031-1065.

Bushee, Brian J., Michael J. Jung, and Gregory S. Miller, 2011, Conference presentations and the disclosure milieu, Journal of Accounting Research 49, 1163-1192.

Campbell, John Y., and Robert J. Shiller, 1988, The dividend-price ratio and expectations of future dividends and discount factors, Review of Financial Studies 1, 195-228.

Campello, Murillo, Chen Lin, Yue Ma, and Hong Zou, 2011, The real and financial implications of corporate hedging, Journal of Finance 66, 1615-1647.

Cravino, Javier, and Andrei A. Levchenko, 2016, Multinational firms and international business cycle transmission, Quarterly Journal of Economics 132, 921-962.

Davis, Steven J., 2017, An index of global economic policy uncertainty, Working Paper, University of Chicago Booth School of Business. 
Dumas, Bernard, Jeff Fleming, and Robert E. Whaley, 1998, Implied volatility functions: Empirical tests, Journal of Finance 53, 2059-2106.

Ghaly, Mohamed, Viet Anh Dang, and Konstantinos Stathopoulos, 2017, Cash holdings and labor heterogeneity: The role of skilled labor, Review of Financial Studies 30, 3636-3668.

Gilchrist, Simon, Jae W. Sim, and Egon Zakrajšek, 2014, Uncertainty, financial frictions, and investment dynamics, National Bureau of Economic Research, Working Paper 20038.

Grossman, Gene, and Carl Shapiro, 1986, Optimal dynamic R\&D programs, The Rand Journal of Economics 581-593.

Gulen, Huseyin, and Mihai Ion, 2016, Policy uncertainty and corporate investment, Review of Financial Studies 29, 523-564.

Hassan, Tarek Alexander, Stephan Hollander, Laurence van Lent, and Ahmed Tahoun, 2020, The global impact of Brexit uncertainty, National Bureau of Economic Research, Working Paper n. 26609.

Hoberg, Gerard, and S. Katie Moon, 2017, Offshore activities and financial vs. operational hedging, Journal of Financial Economics 125, 217-244.

Hoberg, Gerard, and Gordon Phillips, 2016, Text-based network industries and endogenous product differentiation, Journal of Political Economy 124, 1423-1465.

Hollander, Stephan, Maarten Pronk, and Erik Roelofsen, 2010, Does silence speak? An empirical analysis of disclosure choices during conference calls, Journal of Accounting Research 48, 531-563.

Julio, Brandon, and Youngsuk Yook, 2012, Political uncertainty and corporate investment cycles, Journal of Finance 67, 45-83.

Julio, Brandon, and Youngsuk Yook, 2016, Policy uncertainty, irreversibility, and cross-border flows of capital, Journal of International Economics 103, 13-26.

Kim, Hyunseob, and Howard Kung, 2016, The asset redeployability channel: How uncertainty affects corporate investment, Review of Financial Studies 30, 245-280.

Klössner, Stefan, and Rodrigo Sekkel, 2014, International spillovers of policy uncertainty, Economics Letters $124,508-512$.

Kulatilaka, Nalin, and Enrico Perotti, 1998, Strategic growth options, Management Science 44, 1021-1031.

Lee, Jaewoo, and Kwanho Shin, 2000, The role of a variable input in the relationship between investment and uncertainty, American Economic Review 90, 667-680.

Leigh, Nancey Green, and Benjamin R. Kraft, 2018, Emerging robotic regions in the United States: Insights for regional economic evolution, Regional Studies 52, 804-815.

Loughran, Tim, and Bill McDonald, 2011, When is a liability not a liability? Textual analysis, dictionaries, and 10-Ks, Journal of Finance 66, 35-65.

Matsumoto, Dawn, Maarten Pronk, and Erik Roelofsen, 2011, What makes conference calls useful? the information content of managers' presentations and analysts' discussion sessions, The Accounting Review $86,1383-1414$. 
Mihalcea, Rada, and Paul Tarau, 2004, TextRank: Bringing Order Into Text, in Proceedings of the 2004 Conference on Empirical Methods in Natural Language Processing, 404-411.

Mixon, Scott, 2007, The implied volatility term structure of stock index options, Journal of Empirical Finance $14,333-354$.

Vuolteenaho, Tuomo, 2002, What drives firm-level stock returns?, Journal of Finance 57, 233-264.

Wagner, Alexander, Richard J. Zeckhauser, and Alexandre Ziegler, 2018, Company stock reactions to the 2016 election shock: Trump, taxes and trade, Journal of Financial Economics 130, 428-451. 


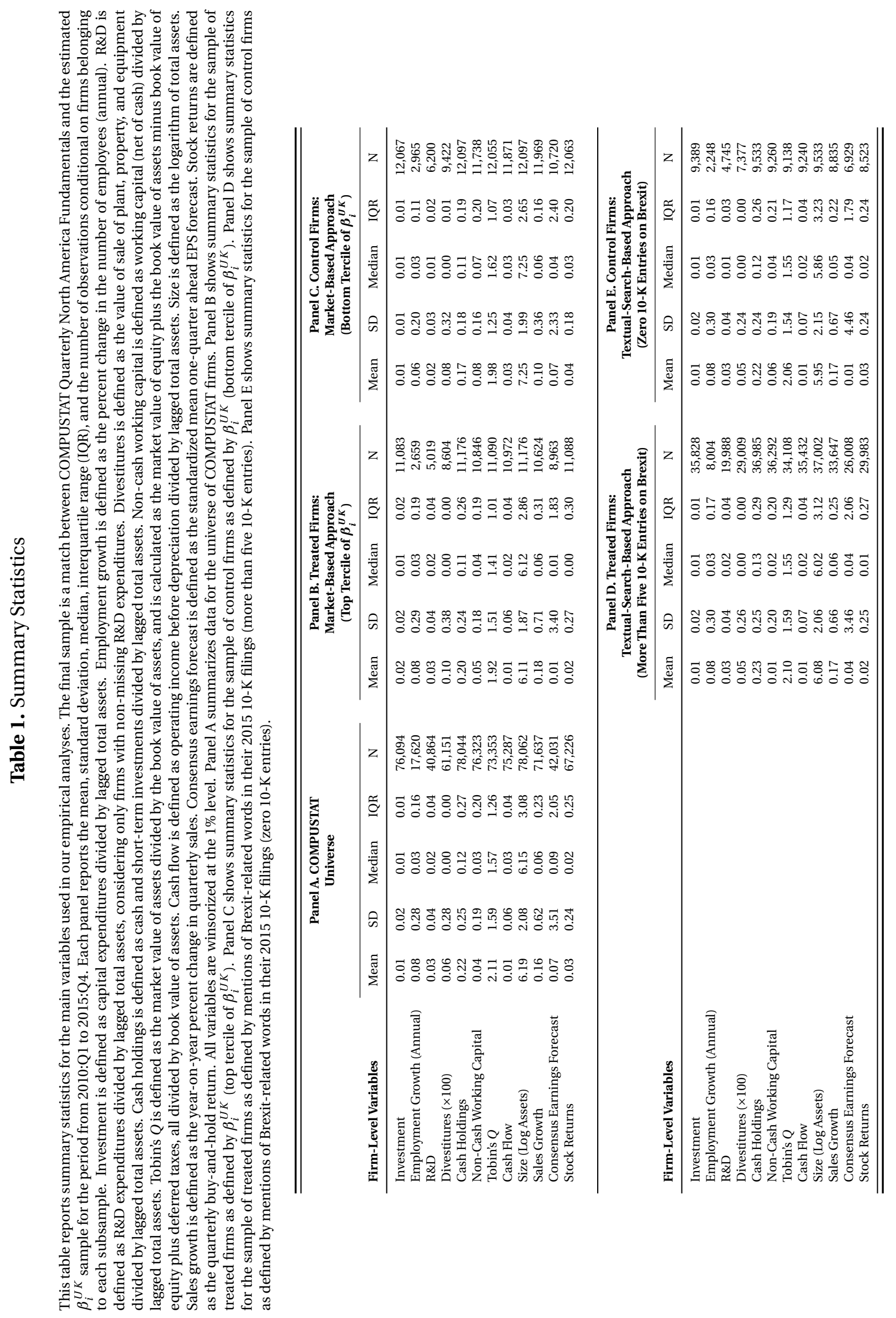




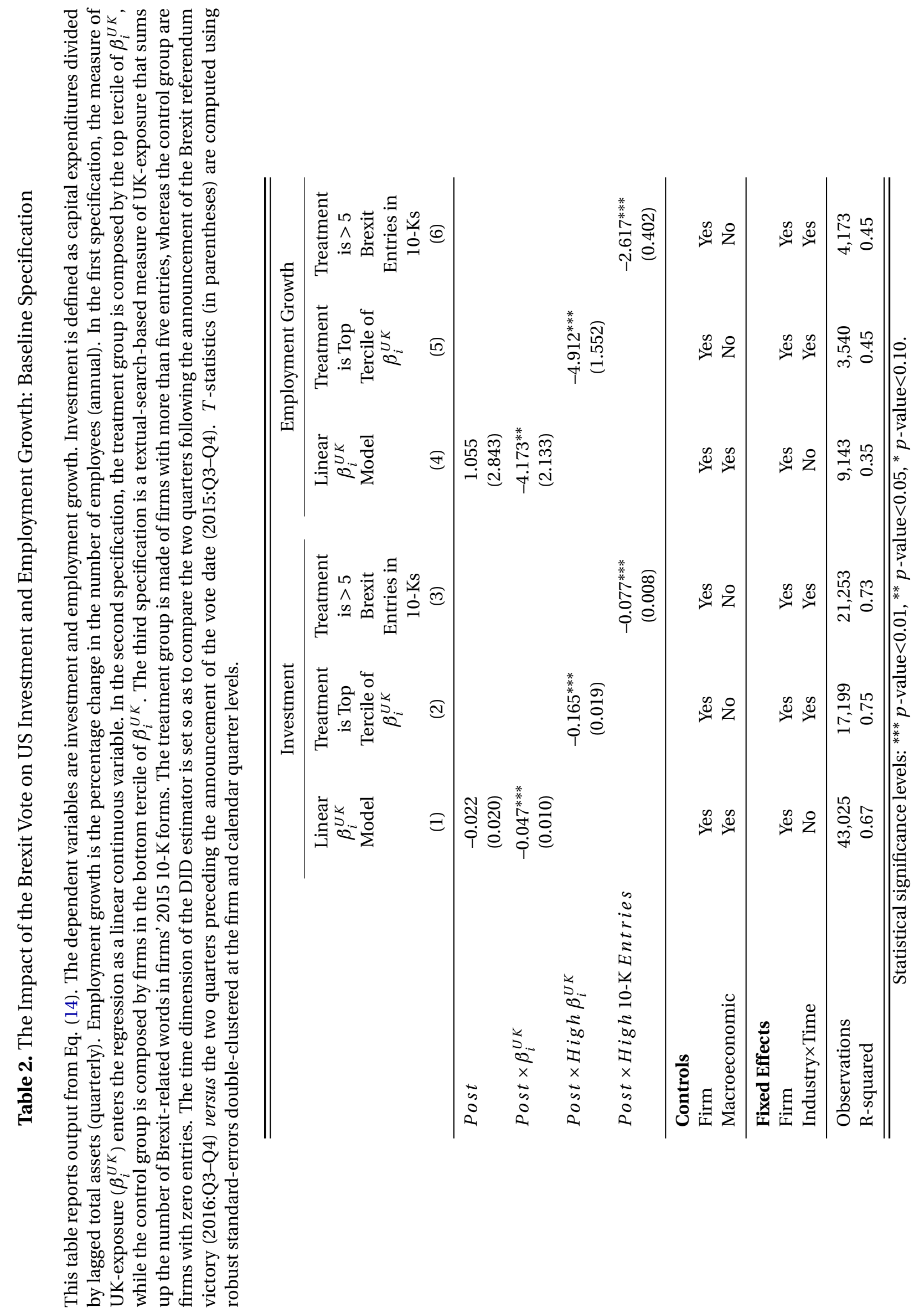




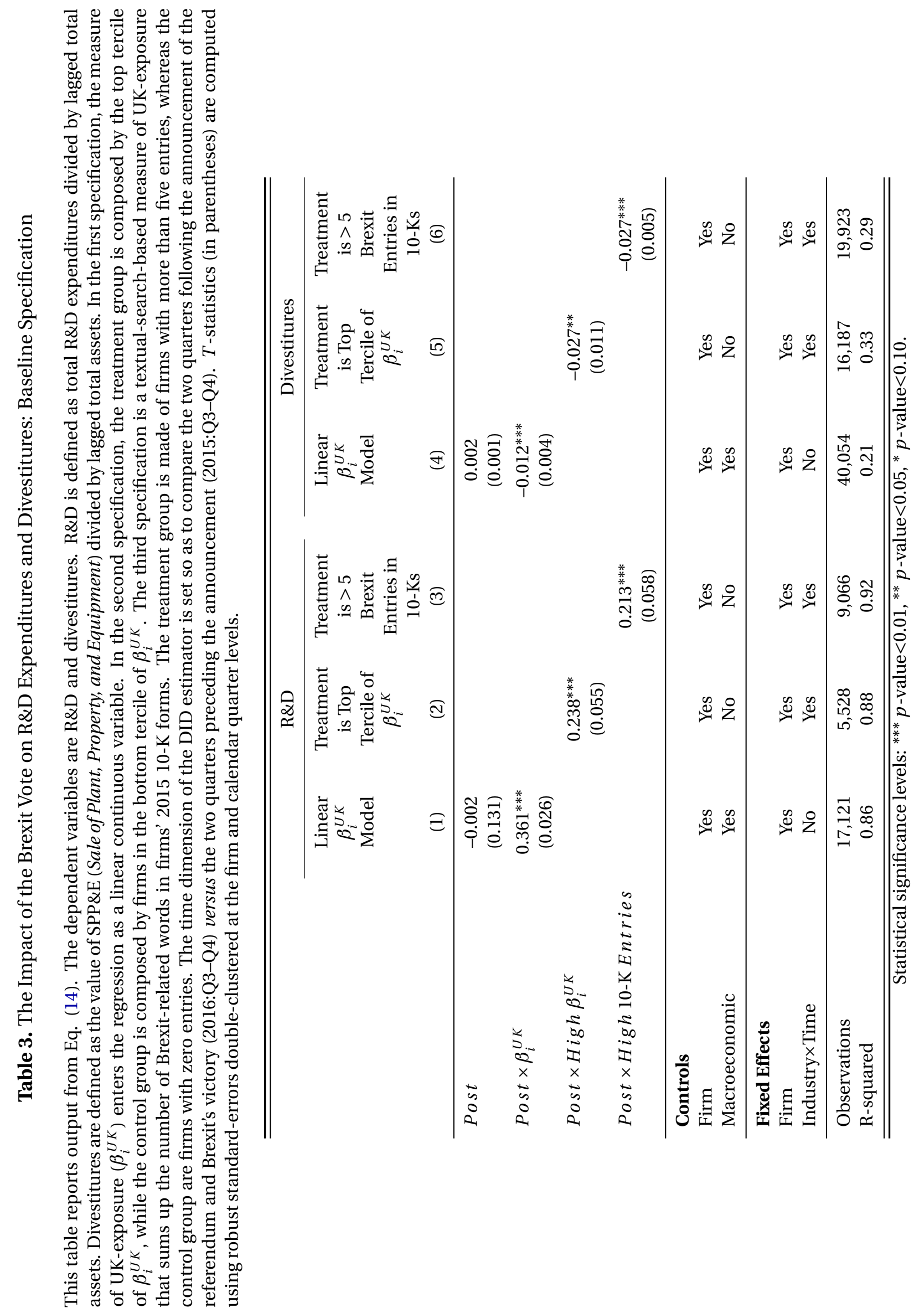




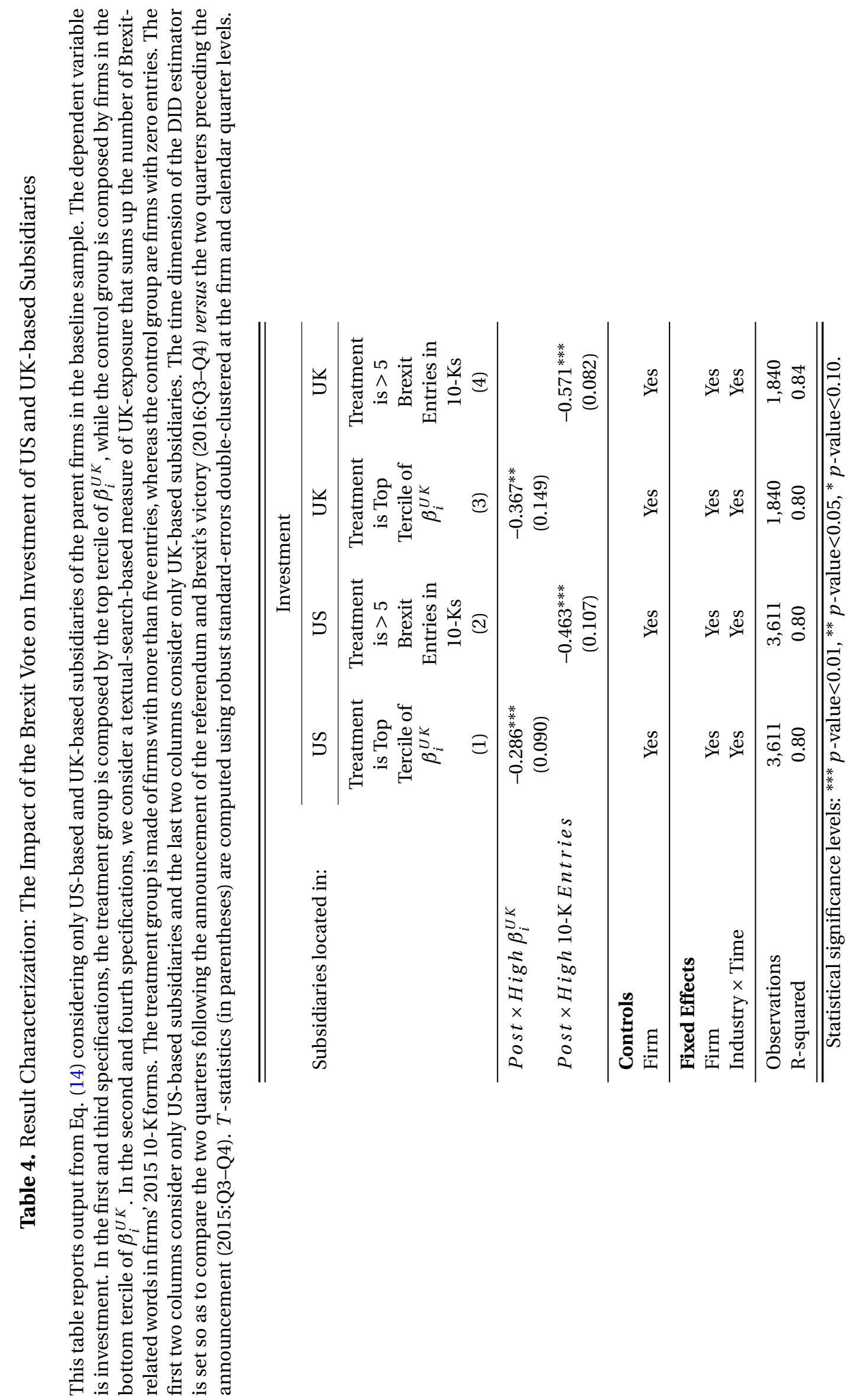




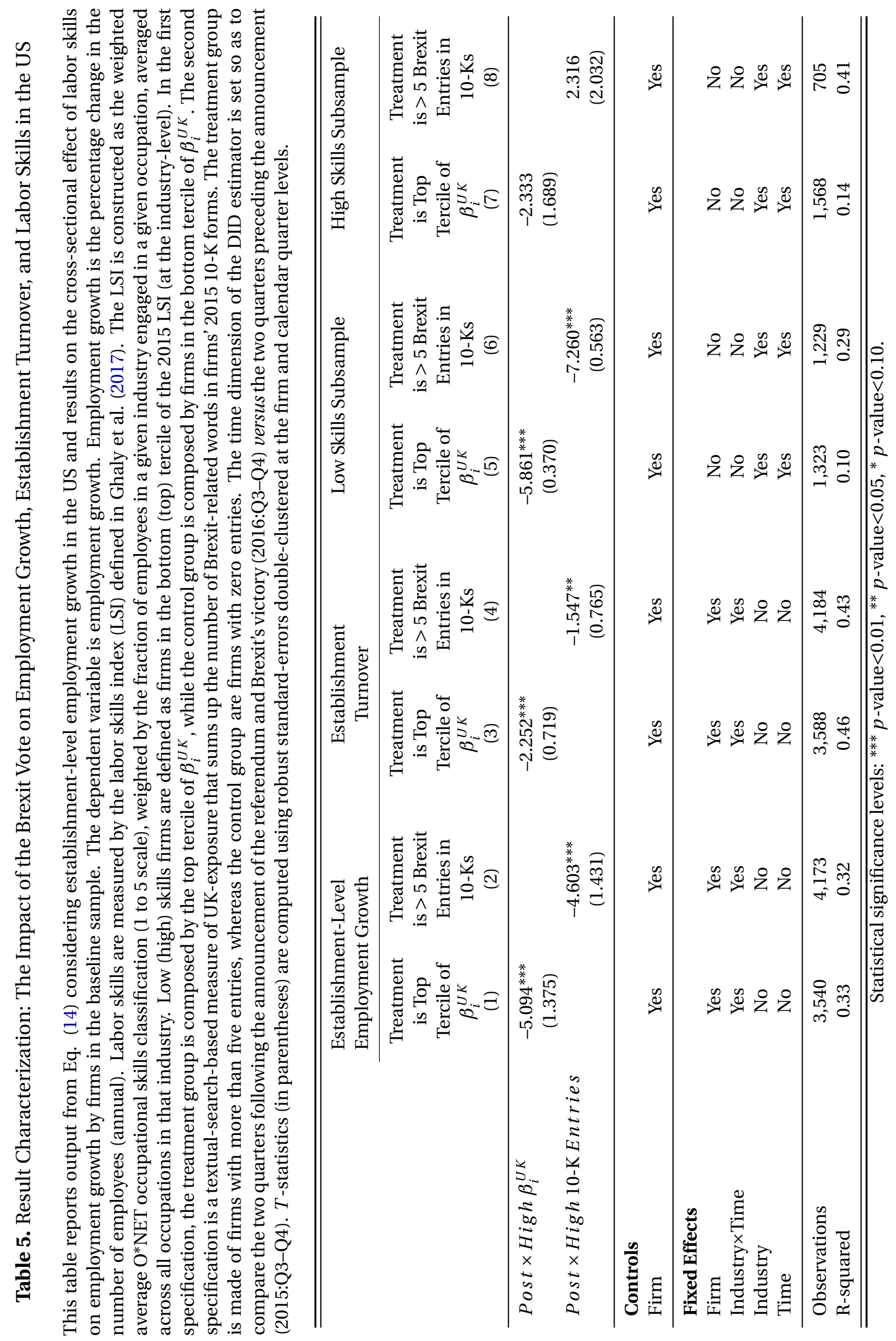




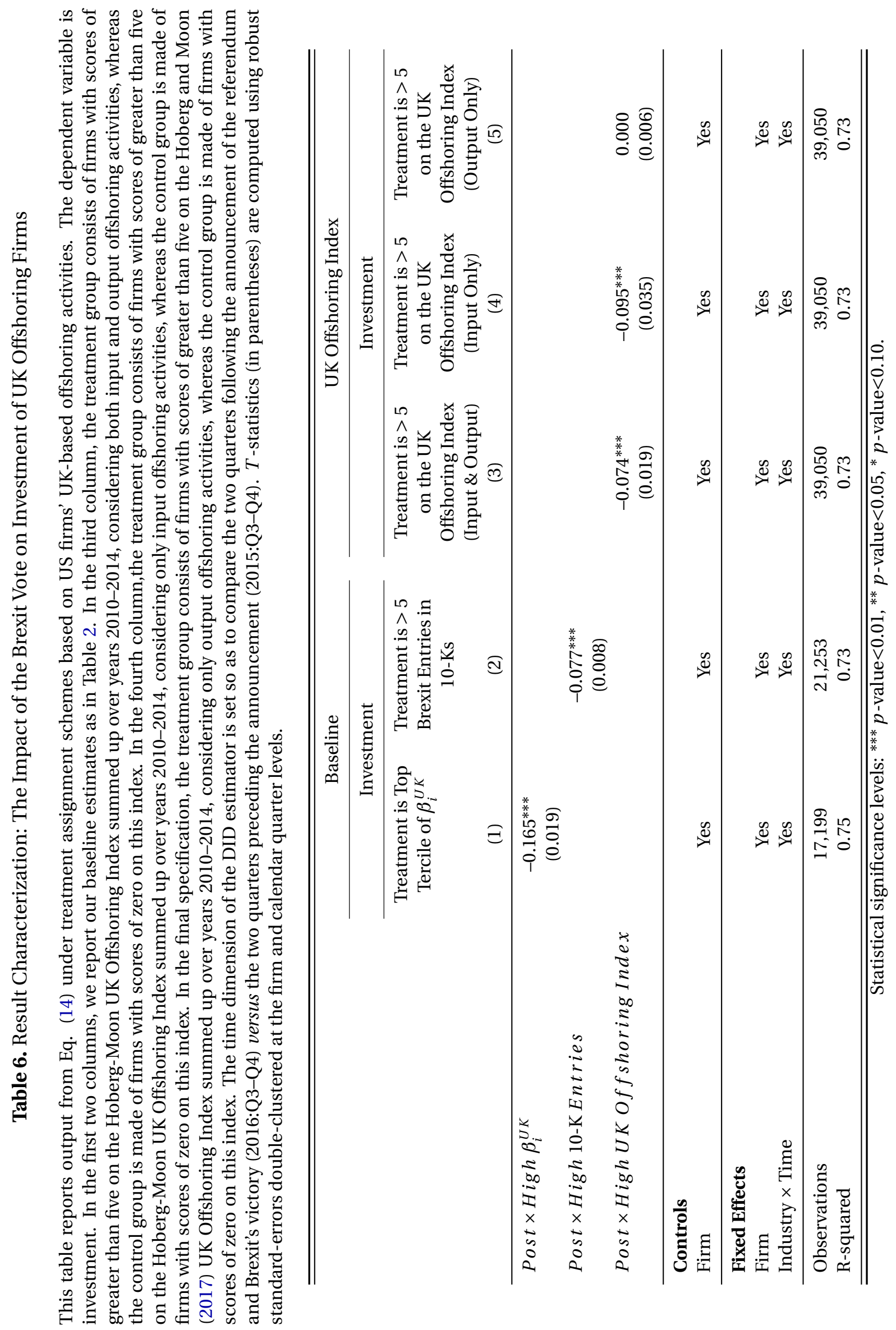




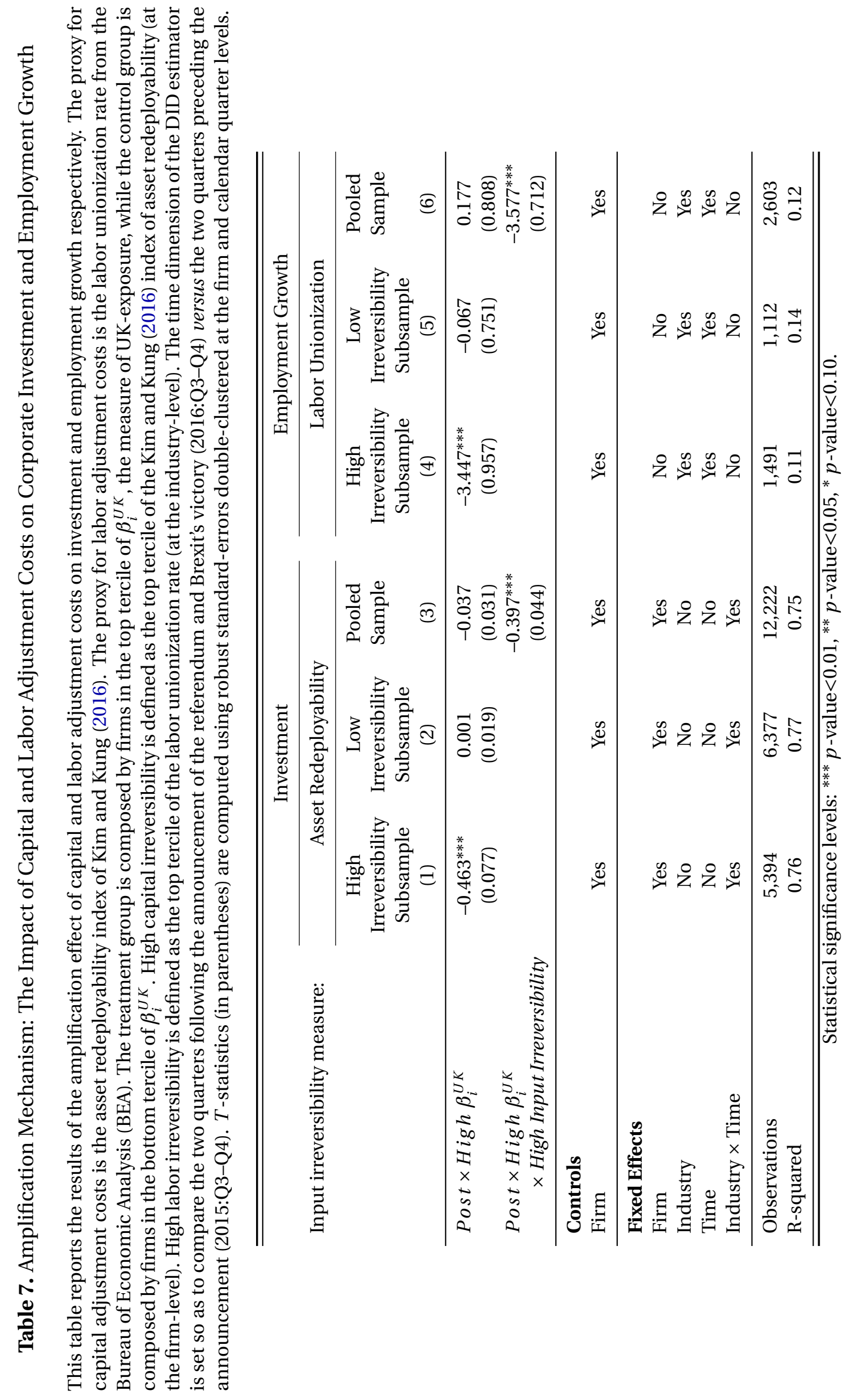




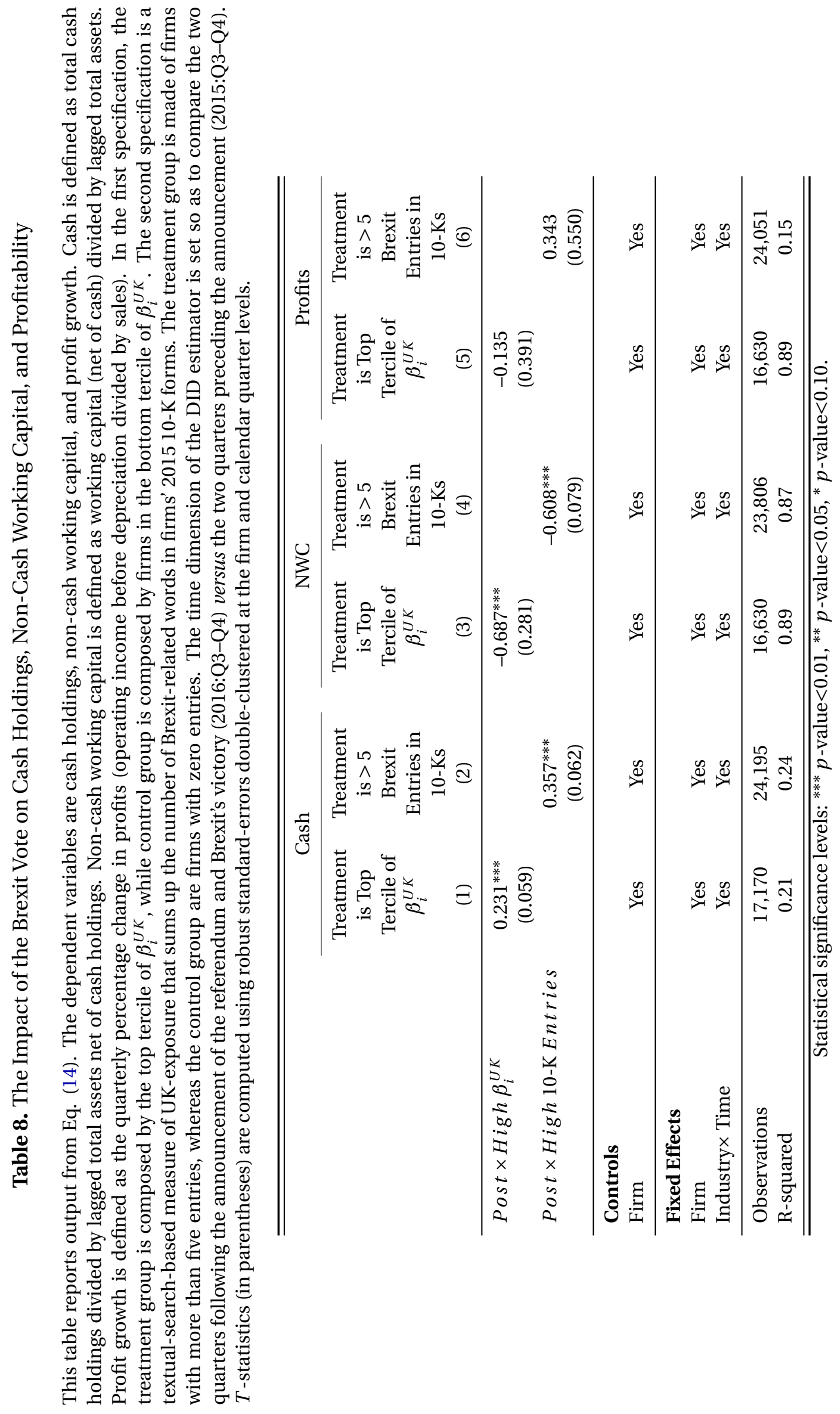




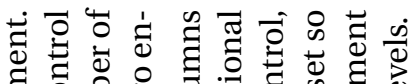

छ ठี

ڤ

.

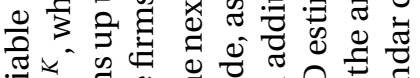

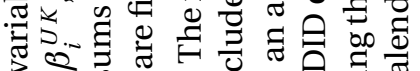

पै कै 它

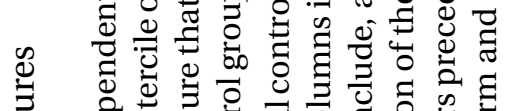

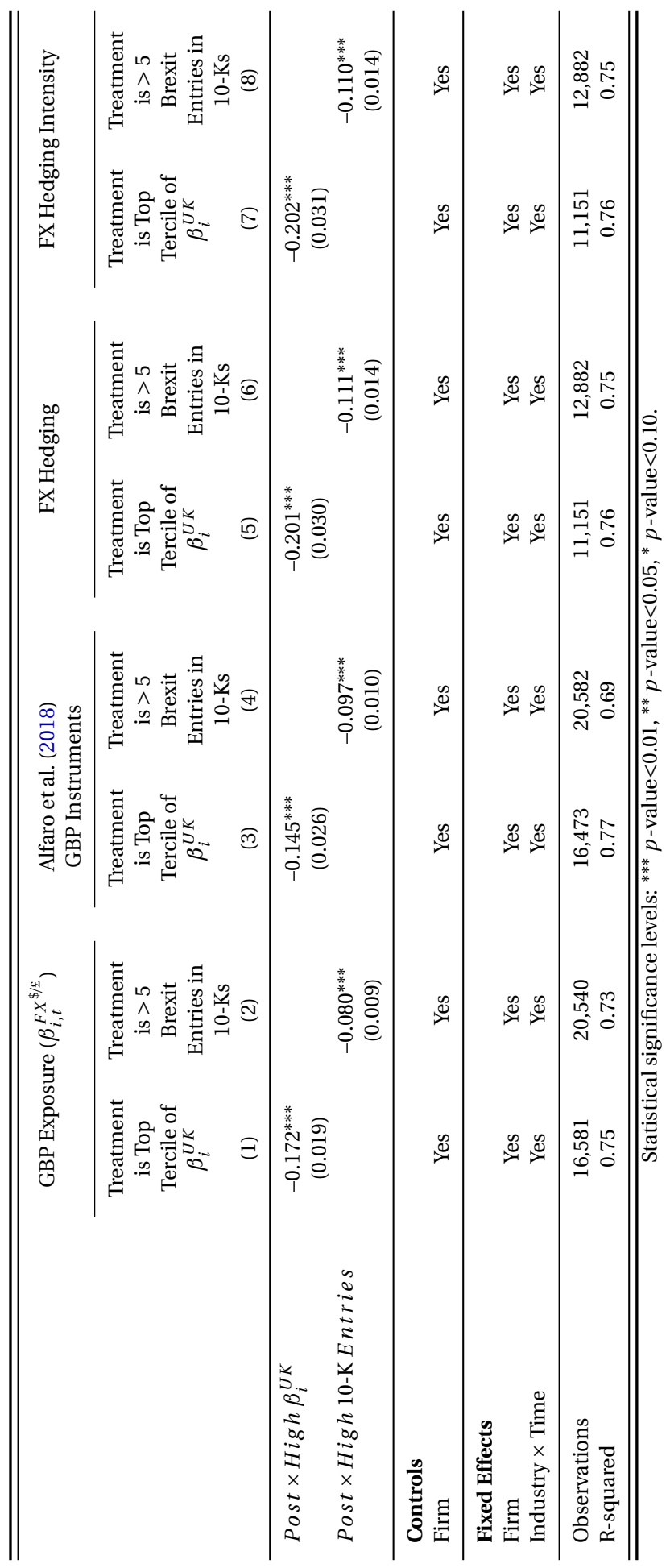

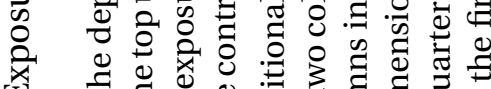

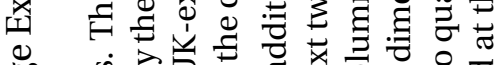

范

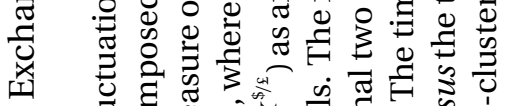

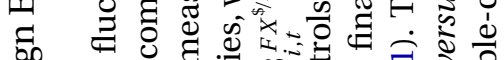

ब.

Iี

車

ఏ

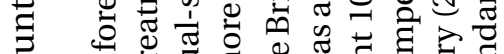

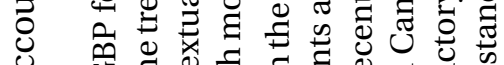

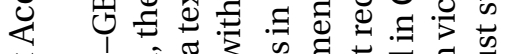

苞 की

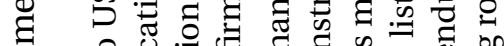

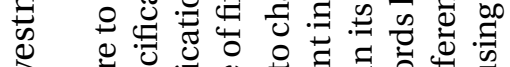

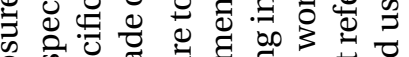

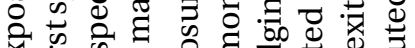

ठ क्षि की की

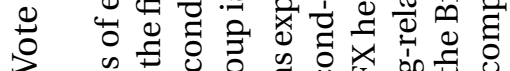

$>\quad 0 \quad 0$ 过

: के

ต

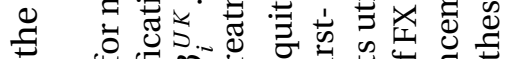

廿

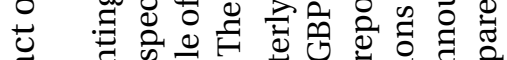

节

过

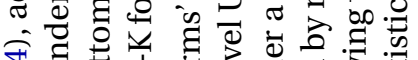

む

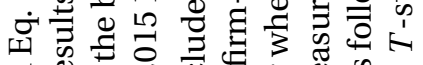

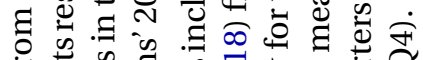

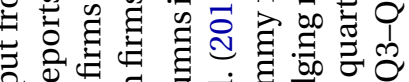

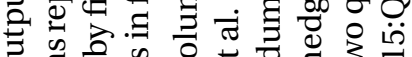

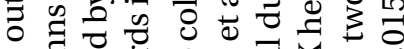

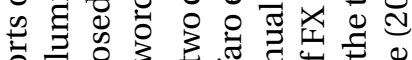

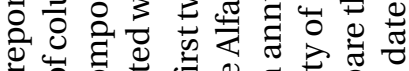
ఖ

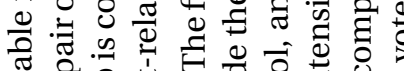

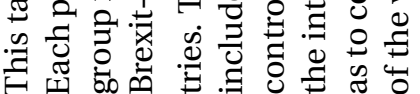




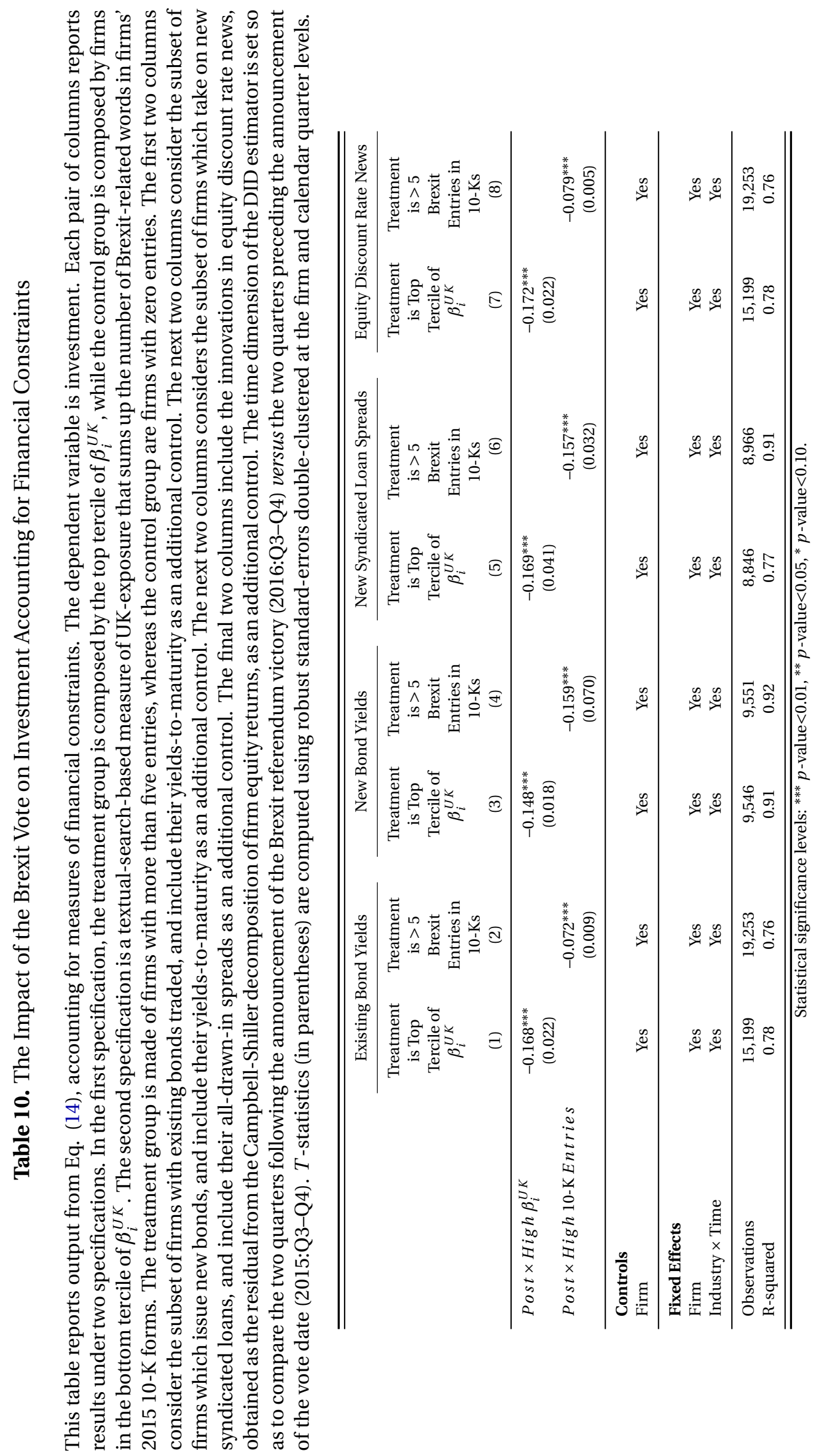




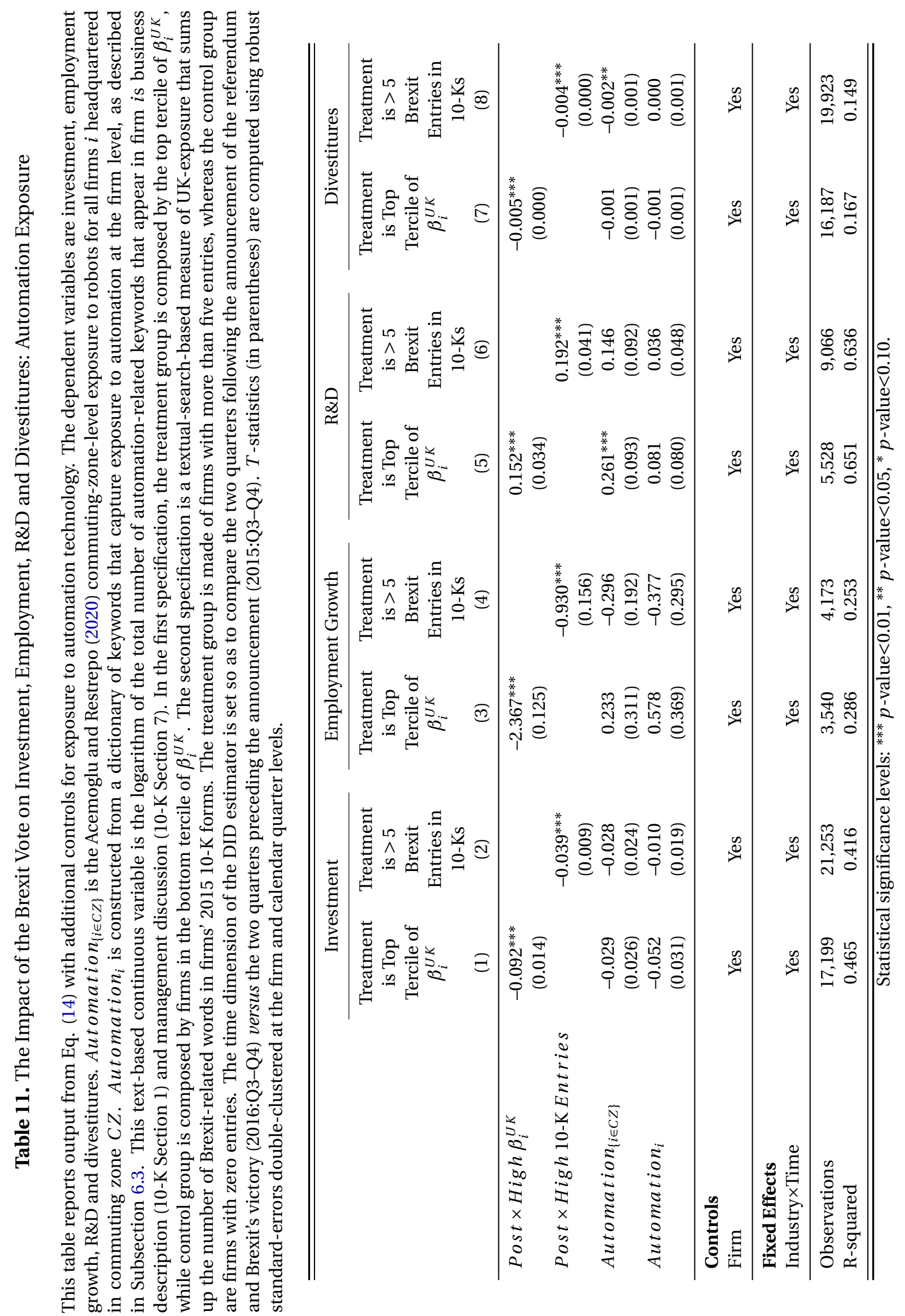




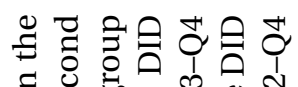

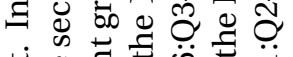

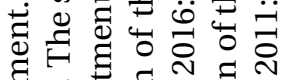

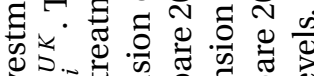

on

के

o

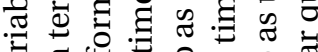

可

范定

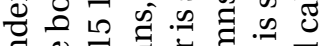

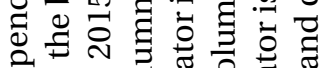

क्ष

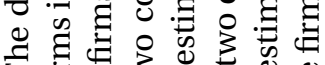

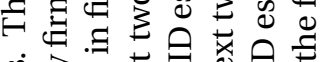

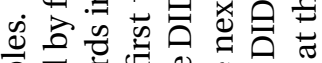

낭

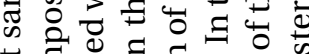

总

.

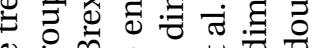

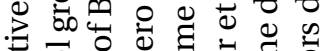

呵

बै

\%

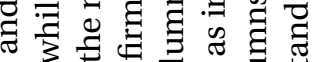

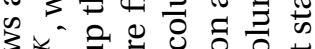

(1)

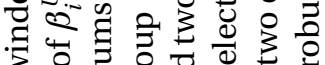

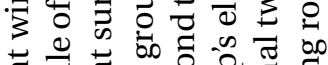

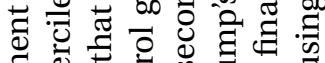

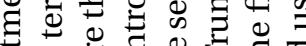

웡 ज्ञ

讨

政

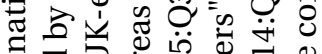

प्षن

\% 3 3

氜

三 口 E

으 형 $\approx$ o

تح

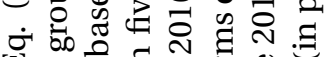

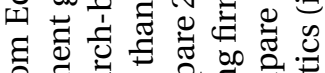

의

政

를

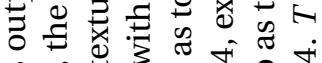

正

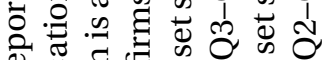

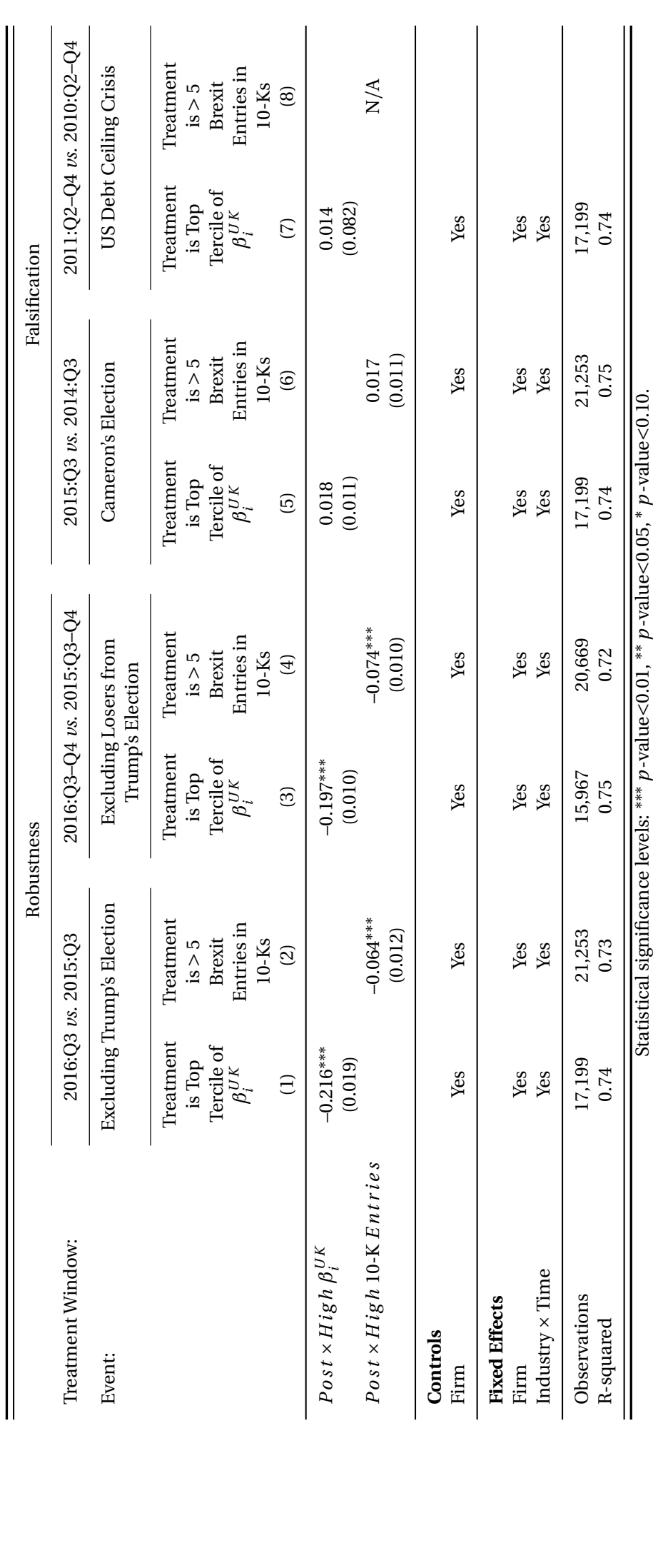

过

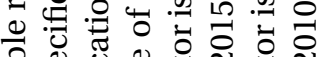

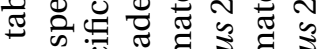
कo 


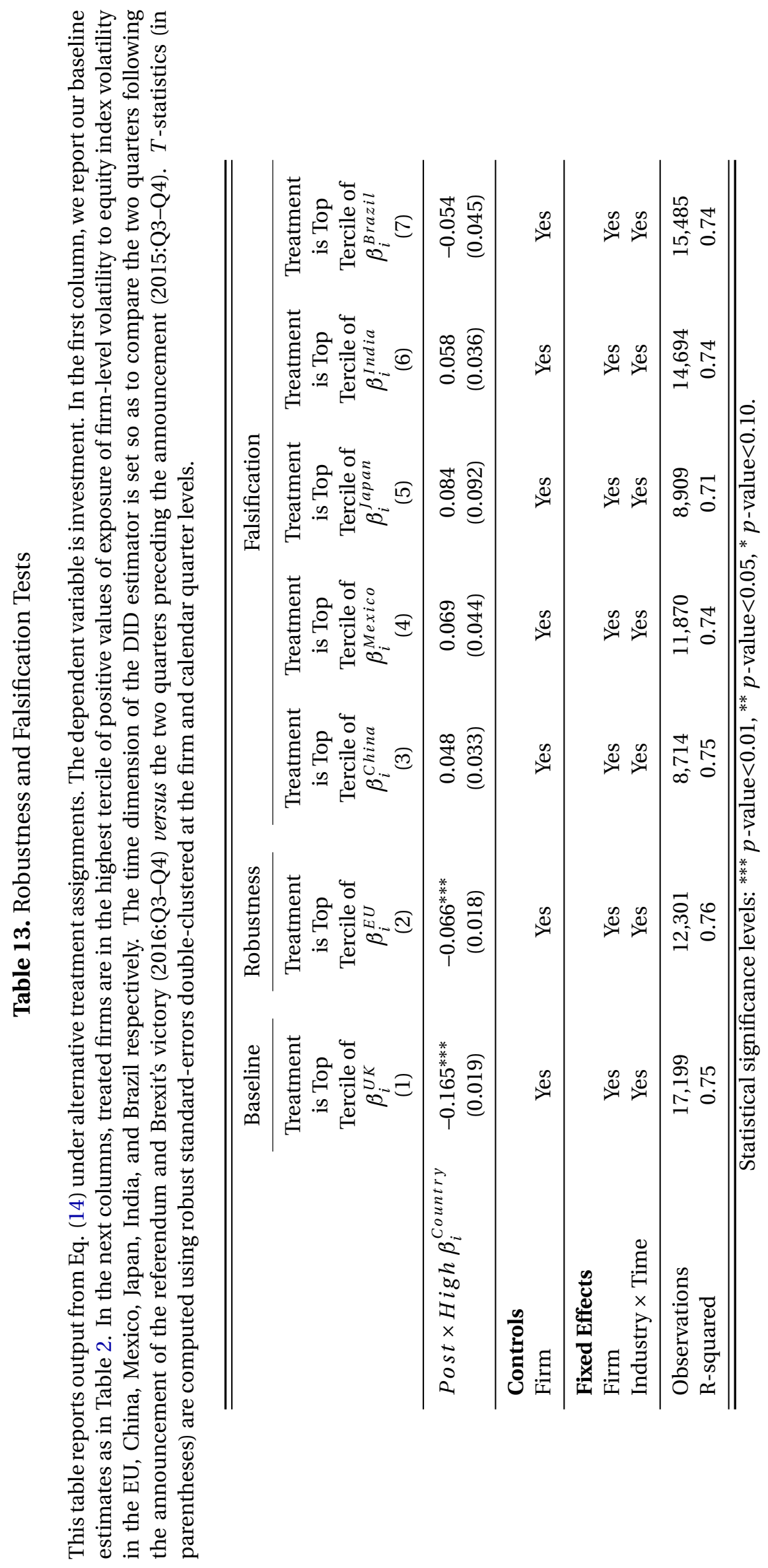




\section{Internet Appendix}

\section{Appendix A Model Analysis and Results}

\section{A.1 Disinvestment Decisions}

In solving a firm's disinvestment problem, we first consider its decision at $t=1$. If the firm had disinvested any of its endowed projects at $t=0$, then it earns 0 for those projects. Among projects that were not disinvested at $t=0$ (i.e., remain alive a $t=1$ ), the firm can choose to sell any of them at $t=1$ and receive cash flows of $s_{i 2}+x_{i 2}-\delta w$ per project. Else, it can choose not to sell and receive $x_{i 2}$ per project. As in the case of the investment decision, the firm's disinvestment policy is guided by the cash flows at $t=2$ generated by project $\tilde{w}$. These cash flows can be characterized as:

$$
\pi_{i 2}(\tilde{w})=\left\{\begin{array}{lll}
0 & & (\text { Early Disinvestment }) \\
s_{i 2}+x_{i 2}-\delta \tilde{w} & \text { if } s_{i 2}>\delta \tilde{w} & (\text { Delayed Disinvestment }) \\
x_{i 2} & \text { if } s_{i 2} \leq \delta \tilde{w} & (\text { No Disinvestment }) .
\end{array}\right.
$$

Next, we consider the firm's disinvestment decision at $t=0$. The optimal level of disinvestment at $t=0$ can be expressed in terms of $w^{*}$, the breakeven project. The firm will optimally disinvest (sell) all projects in the range $\left[0, w^{*}\right.$ ), and not disinvest (choose to retain) any projects in the range $\left[w^{*}, W\right]$, instead of waiting until $t=1$ to decide whether or not to disinvest. The firm's cash flows from disinvesting project $\tilde{w}$ at $t=0$ is $s_{i 1}+x_{i 1}-\delta \tilde{w}$. Its expected cash flows from not disinvesting project $\tilde{w}$ at $t=0$, and choosing instead to wait till $t=1$ to decide, is $x_{i 1}+\mathbb{E}\left[\max \left(s_{i 2}+x_{i 2}-\delta \tilde{w}, x_{i 2}\right)\right]$. Simplifying these two expressions, the firm disinvests project $\tilde{w}$ at $t=0$ if:

$$
s_{i 1}-\delta \tilde{w} \geq x_{i 2}+\mathbb{E}\left[\max \left(s_{i 2}-\delta \tilde{w}, 0\right)\right] .
$$

The breakeven condition for determining the optimal disinvestment level $w^{*}$ at $t=0$ is:

$$
s_{i 1}-\delta w^{*}=x_{i 2}+\mathbb{E}\left[\max \left(s_{i 2}-\delta w^{*}, 0\right)\right] .
$$

In Lemma 3, we prove the existence of the optimal $t=0$ investment level, $w^{*}$.

Lemma 3. The optimal disinvestment level $w^{*}$ at $t=0$ is given by (A.3) for sufficiently large $W$.

The breakeven condition in (A.3) implies that at $t=0$ the firm sells all projects up to project $w^{*}$, as the benefits of doing so, $s_{i 1}$, are expected to exceed the costs. Costs are made of two components: (1) the cost of selling the project, $\delta w$, and (2) the option value of waiting to choose whether to disinvest. The embedded optionality in the firm's disinvestment decision is key in generating a negative relation between uncertainty and disinvestment, as is the case with investment. As before, while the addition of a zero-mean spread does not change the left-hand side of (A.2), it increases the right-hand side of that inequality given the firm's option to forgo disinvestment in high income states. An increase in uncertainty in the distribution of $s_{i t}$ reduces the breakeven project level $w^{*}$, and correspondingly shrinks the set of projects the firm disinvests at $t=0$, namely the interval $\left[0, w^{*}\right)$. We establish this result in Proposition 3.

Proposition 3. Increased uncertainty leads to less disinvestment at $t=0$. For $r^{\prime}>r$, namely when $G\left(\cdot, r^{\prime}\right)$ is obtained by a mean-preserving spread of $G(\cdot, r), w^{*}\left(r^{\prime}\right)<w^{*}(r)$. That is, $\frac{d w^{*}}{d r}<0$.

Taken together, the results of Proposition 1 and 3 imply that by increasing the value of the option to wait, greater uncertainty leads to decreases in both investment and disinvestment.

\section{A.2 The Effect of Input Irreversibility}

We now address the role played by the degree of irreversibility of capital and labor, as captured by their associated fixed costs. We do so by way of two propositions.

Proposition 4. An increase in the degree of irreversibility of capital leads to less investment for higher levels of uncertainty in the first period; i.e., $\frac{d n^{*}}{d \kappa}<0$. 
Proposition 5. An increase in the degree of irreversibility of labor leads to less investment for higher levels of uncertainty in the first period; i.e., $\frac{d n^{*}}{d \lambda}<0$.

Combining the last two propositions with Proposition 1, we have that for an increase in uncertainty in the MPS sense (i.e., $r^{\prime}>r$ ) and for greater degree of input irreversibility $\left(\kappa^{\prime}>\kappa\right.$ and $\left.\lambda^{\prime}>\lambda\right)$, the following conditions hold with respect to investment:

$$
\begin{aligned}
& n^{*}(r, \kappa, \lambda)>n^{*}\left(r^{\prime}, \kappa, \lambda\right)>n^{*}\left(r^{\prime}, \kappa^{\prime}, \lambda\right), \\
& n^{*}(r, \kappa, \lambda)>n^{*}\left(r^{\prime}, \kappa, \lambda\right)>n^{*}\left(r^{\prime}, \kappa, \lambda^{\prime}\right) .
\end{aligned}
$$

The above conditions state that an increase in uncertainty reduces the set of projects the firm is willing to invest in at $t=0$, electing to wait until uncertainty is partially resolved at $t=1$ before deciding whether to invest. Notably, when the firm faces higher irreversible costs, it invests even less at $t=0$. Differently put, an increase in uncertainty reduces investment in the first period, and the effect is modulated by the degree of irreversibility of capital or labor. 


\section{Appendix B Proofs}

\section{B.1 Proof of Lemma 1}

Proof. Let us define

$$
H\left(n^{*}\right)=v_{i 1}+\mathbb{E}\left[v_{i 2}\right]-(\kappa+\lambda) n^{*}-\mathbb{E}\left[\max \left(v_{i 2}-(\kappa+\lambda) n^{*}, 0\right)\right] .
$$

To guarantee the existence of $n^{*}$ as characterized by (6), it suffices to show that $H\left(n^{*}\right)=0$ for some $n^{*} \in$ $[0, N]$. Since $H(\cdot)$ is a sum of continuous functions, it is itself continuous. Since $v_{i 1}>0$ and $v_{i 2}>0$, it follows that:

Finally, for $N \rightarrow \infty$, we have that:

$$
H(0)=v_{i 1}+\mathbb{E}\left[v_{i 2}\right]-\mathbb{E}\left[\max \left(v_{i 2}, 0\right)\right]=v_{i 1}>0 .
$$

$$
\begin{aligned}
\lim _{N \rightarrow \infty} H(N) & =\lim _{N \rightarrow \infty}\left(v_{i 1}+\mathbb{E}\left[v_{i 2}\right]-(\kappa+\lambda) N\right)+\lim _{N \rightarrow \infty}\left(\mathbb{E}\left[\max \left(v_{i 2}-(\kappa+\lambda) N, 0\right)\right]\right) \\
& =-\infty+0=-\infty .
\end{aligned}
$$

Thus, there must exist an $\bar{N} \in \mathbb{R}$ such that, for $N>\bar{N}, H(\bar{N})<0$. Putting these conditions together with the continuity of $H(\cdot)$ over $[0, N]$, the Intermediate Value Theorem guarantees that there exists an $n^{*} \in[0, N]$ such that $H\left(n^{*}\right)=0$.

\section{B.2 Proof of Proposition 1}

Proof. Let us define

$$
H\left(n^{*} ; r\right)=v_{i 1}+\mathbb{E}\left[v_{i 2}\right]-(\kappa+\lambda) n^{*}-\mathbb{E}\left[\max \left(v_{i 2}-(\kappa+\lambda) n^{*}, 0\right) ; r\right]=0
$$

By the Implicit Function Theorem,

$$
\frac{d n^{*}}{d r}=-\frac{\partial H / \partial n^{*}}{\partial H / \partial r}
$$

Considering first the derivative of $H$ with respect to $n^{*}$, we have:

$$
\begin{aligned}
\frac{\partial H\left(n^{*} ; r\right)}{\partial n^{*}} & =-(\kappa+\lambda)-\frac{\partial}{\partial n^{*}} \mathbb{E}\left[\max \left(v_{i 2}-(\kappa+\lambda) n^{*}, 0\right) ; r\right] \\
& =-(\kappa+\lambda)-\mathbb{E}\left[\frac{\partial}{\partial n^{*}} \max \left(v_{i 2}-(\kappa+\lambda) n^{*}, 0\right) ; r\right] \\
& =-(\kappa+\lambda)-\mathbb{E}\left[\max \left(v_{i 2}-(\kappa+\lambda), 0\right) ; r\right] \\
& <0 .
\end{aligned}
$$

Next, considering the derivative of $H$ with respect to $r$, we have:

$$
\frac{\partial H\left(n^{*} ; r\right)}{\partial r}=-\frac{\partial}{\partial r} \mathbb{E}\left[\max \left(v_{i 2}-(\kappa+\lambda) n^{*}, 0\right) ; r\right] .
$$

Because $G\left(\cdot, r^{\prime}\right)$ is a MPS of $G(\cdot, r)$, for any convex function $J(\cdot)$,

$$
\begin{aligned}
\mathbb{E}\left[J\left(v_{i 2}\right) ; r^{\prime}\right] & =\int J\left(v_{i 2}\right) d G\left(v_{i 2}, r^{\prime}\right) \\
& \geq \int J\left(v_{i 2}\right) d G\left(v_{i 2}, r\right) \\
& =\mathbb{E}\left[J\left(v_{i 2}\right) ; r\right] .
\end{aligned}
$$

Since $\max \left(v_{i 2}-(\kappa+\lambda) n^{*}, 0\right)$ is convex in $v_{i 2}$, it follows that:

$$
\mathbb{E}\left[\max \left(v_{i 2}-(\kappa+\lambda) n^{*}, 0\right) ; r^{\prime}\right] \geq \mathbb{E}\left[\max \left(v_{i 2}-(\kappa+\lambda) n^{*}, 0\right) ; r\right] \forall r^{\prime}>r .
$$

This implies

Thus,

$$
\frac{\partial}{\partial r} \mathbb{E}\left[\max \left(v_{i 2}-(\kappa+\lambda) n^{*}, 0\right) ; r\right] \geq 0 .
$$

$$
\begin{aligned}
\frac{\partial H\left(n^{*} ; r\right)}{\partial r} & =-\frac{\partial}{\partial r} \mathbb{E}\left[\max \left(v_{i 2}-(\kappa+\lambda) n^{*}, 0\right) ; r\right] \\
& \leq 0 .
\end{aligned}
$$


Putting these conditions together, we have:

$$
\frac{d n^{*}}{d r}=-\frac{\partial H / \partial n^{*}}{\partial H / \partial r}<0
$$

\section{B.3 Proof of Proposition 2}

Proof. Rearranging Eq. (10), we get:

It can be shown that $\frac{d m^{*}}{d r}>0$ as:

$$
m^{*}=\frac{1}{\alpha}\left(\overline{u_{i 1}}-d_{1}-d_{2}+u_{i 1}+\frac{\sqrt{\omega_{i}^{2}(r)+\sigma_{x}^{2}}}{1-\Phi\left(\frac{d_{2}-\overline{u_{i 1}}}{\sqrt{\omega_{i}^{2}(r)+\sigma_{x}^{2}}}\right)}\left[\phi\left(\frac{d_{2}-\overline{u_{i 1}}}{\sqrt{\omega_{i}^{2}(r)+\sigma_{x}^{2}}}\right)\right]\right)^{\frac{1}{\alpha-1}}
$$

$$
\phi\left(\frac{d_{2}-\overline{u_{i 1}}}{\sqrt{\omega_{i}^{2}(r)+\sigma_{x}^{2}}}\right)\left[1-\frac{\left(\frac{d_{2}-\overline{u_{i 1}}}{\sqrt{\omega_{i}^{2}(r)+\sigma_{x}^{2}}}\right) \phi\left(\frac{d_{2}-\overline{u_{i 1}}}{\sqrt{\omega_{i}^{2}(r)+\sigma_{x}^{2}}}\right)}{1-\Phi\left(\frac{d_{2}-\overline{u_{i 1}}}{\sqrt{\omega_{i}^{2}(r)+\sigma_{x}^{2}}}\right)}\right]-\phi^{\prime}\left(\frac{d_{2}-\overline{u_{i 1}}}{\sqrt{\omega_{i}^{2}(r)+\sigma_{x}^{2}}}\right)\left(\frac{d_{2}-\overline{u_{i 1}}}{\sqrt{\omega_{i}^{2}(r)+\sigma_{x}^{2}}}\right)>0 .
$$

\section{B.4 Proof of Proposition 4}

Proof. Let us define

$$
H\left(n^{*} ; \kappa\right)=v_{i 1}+\mathbb{E}\left[v_{i 2}\right]-(\kappa+\lambda) n^{*}-\mathbb{E}\left[\max \left(v_{i 2}-(\kappa+\lambda) n^{*}, 0\right)\right]=0 .
$$

By the Implicit Function Theorem,

$$
\frac{d n^{*}}{d \kappa}=-\frac{\partial H / \partial n^{*}}{\partial H / \partial \kappa} .
$$

Considering first the numerator, we know from Proposition 1 that:

Next, considering the denominator,

$$
\frac{\partial H}{\partial n^{*}}<0
$$

Putting these together, we have:

$$
\begin{aligned}
\frac{\partial H}{\partial \kappa} & =-n^{*}-\frac{\partial}{\partial \kappa} \mathbb{E}\left[\max \left(v_{i 2}-(\kappa+\lambda) n^{*}, 0\right)\right] \\
& =-n^{*}-\mathbb{E}\left[\frac{\partial}{\partial \kappa} \max \left(v_{i 2}-(\kappa+\lambda) n^{*}, 0\right)\right] \\
& =-n^{*}-\mathbb{E}\left[\max \left(v_{i 2}-n^{*}, 0\right)\right] \\
& <0 .
\end{aligned}
$$

$$
\frac{d n^{*}}{d \kappa}=-\frac{\partial H / \partial n^{*}}{\partial H / \partial \kappa}<0
$$

\section{B.5 Proof of Proposition 5}

Proof. Symmetric to the case of capital. 


\section{Appendix C Additional Results and Robustness Tests}

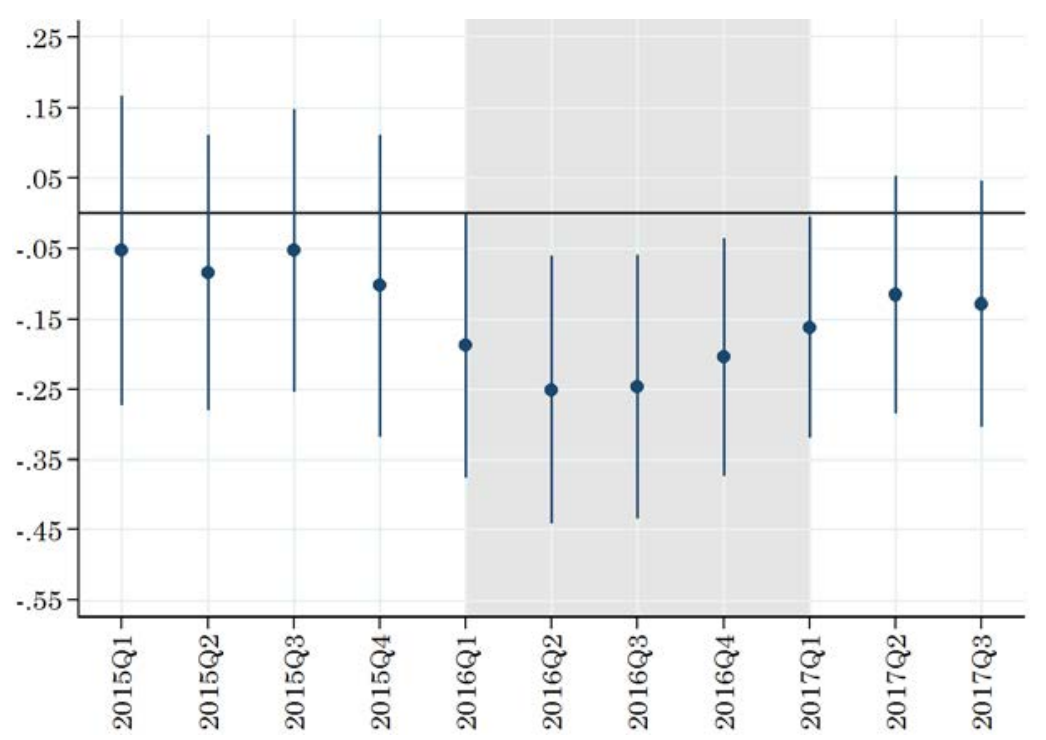

Figure C.1. Corporate Investment Trends around Brexit-related Events. This figure displays coefficients of investment regressions for the timeline of the main events related to Brexit. The shaded area marks the beginning of Brexit-related events, with the announcement of the date of the UK-EU referendum (2016:Q1). 
Table C.1. Sample Selection

This table reports the filters applied to the original dataset obtained from COMPUSTAT, and the number of observations obtained at each step in order to generate the baseline sample described in Section 4.2.

\begin{tabular}{lr}
\hline \hline Filter & Firm-Quarters \\
\hline Raw COMPUSTAT between 2010:Q1 and 2016:Q4 & 262,412 \\
Drop non-US firm-quarters (retain data reported in USD, with US headquarters, duplicates excluded) & 160,254 \\
Drop firm-quarters with negative fundamentals (assets and sales) & 158,312 \\
Drop financials and utilities & 112,939 \\
Drop if assets or market capitalization less than \$10 million & 93,011 \\
Drop if missing key variables (investment, assets, cash flow, Tobin's Q, sales growth) & 75,013 \\
Drop if non-consecutive quarters, or less than 12 quarters of non-missing data & 56,081 \\
Drop if missing Hoberg and Phillips (2016) industry classification & 49,107 \\
Drop if missing $\beta_{i}^{U K}$ & 43,025 \\
Drop if missing CRSP and I/B/E/S controls & 41,630 \\
\hline \hline
\end{tabular}


Table C.2. Summary Statistics: Matched Sample

This table reports mean values for the main variables used in our empirical analyses in the matched sample. Each treated firm is matched to 3 control firms (with replacement) which are its nearest neighbors in terms of treatment propensity. The propensity score is a function of lagged returns, 1-quarter-ahead consensus earnings forecast, Tobin's $Q$, cash flow, sales growth, and size. Panel A shows summary statistics for the sample of treated and matched control firms as defined by $\beta_{i}^{U K}$ (top tercile of $\beta_{i}^{U K}$ ). Panel B shows summary statistics for the sample of treated and matched control firms as defined by mentions of Brexit-related words in their 2015 10-K filings. The table also reports the differences in means and the $p$-value associated with a test statistic for the differences.

\begin{tabular}{|c|c|c|c|c|}
\hline Firm-Level Variables & Treated & Control & Difference & $p$-value \\
\hline & \multicolumn{4}{|c|}{ Panel A: Market-Based Approach } \\
\hline Investment & 0.020 & 0.012 & 0.008 & 0.251 \\
\hline Employment Growth (Annual) & 0.083 & 0.061 & 0.022 & 0.424 \\
\hline $\mathrm{R} \& \mathrm{D}$ & 0.030 & 0.016 & 0.014 & 0.385 \\
\hline Divestitures $(\times 100)$ & 0.129 & 0.088 & 0.041 & 0.404 \\
\hline Cash Holdings & 0.175 & 0.164 & 0.011 & 0.410 \\
\hline Non-Cash Working Capital & 0.058 & 0.086 & -0.028 & 0.272 \\
\hline Tobin’s $Q$ & 1.948 & 1.928 & 0.020 & 0.383 \\
\hline Cash Flow & 0.016 & 0.032 & -0.016 & 0.610 \\
\hline Size (Log Assets) & 6.677 & 7.205 & -0.528 & 0.528 \\
\hline Sales Growth & 0.195 & 0.105 & 0.090 & 0.203 \\
\hline Consensus Earnings Forecast & 0.023 & 0.025 & -0.002 & 0.594 \\
\hline \multirow[t]{2}{*}{ Stock Returns } & 0.021 & 0.038 & -0.017 & 0.618 \\
\hline & \multicolumn{4}{|c|}{ Panel B: Textual-Search-Based Approach } \\
\hline Investment & 0.013 & 0.014 & 0.000 & 0.269 \\
\hline Employment Growth (Annual) & 0.084 & 0.078 & 0.006 & 0.429 \\
\hline $\mathrm{R} \& \mathrm{D}$ & 0.030 & 0.022 & 0.008 & 0.749 \\
\hline Divestitures $(\times 100)$ & 0.062 & 0.056 & 0.006 & 0.210 \\
\hline Cash Holdings & 0.232 & 0.194 & 0.038 & 0.339 \\
\hline Non-Cash Working Capital & 0.041 & 0.057 & -0.016 & 0.522 \\
\hline Tobin’s $Q$ & 2.199 & 2.037 & 0.162 & 0.166 \\
\hline Cash Flow & 0.018 & 0.021 & -0.003 & 0.836 \\
\hline Size (Log Assets) & 7.059 & 6.581 & 0.478 & 0.293 \\
\hline Sales Growth & 0.162 & 0.167 & -0.005 & 0.605 \\
\hline Consensus Earnings Forecast & 0.055 & 0.023 & 0.032 & 0.137 \\
\hline Stock Returns & 0.028 & 0.030 & -0.002 & 0.758 \\
\hline
\end{tabular}




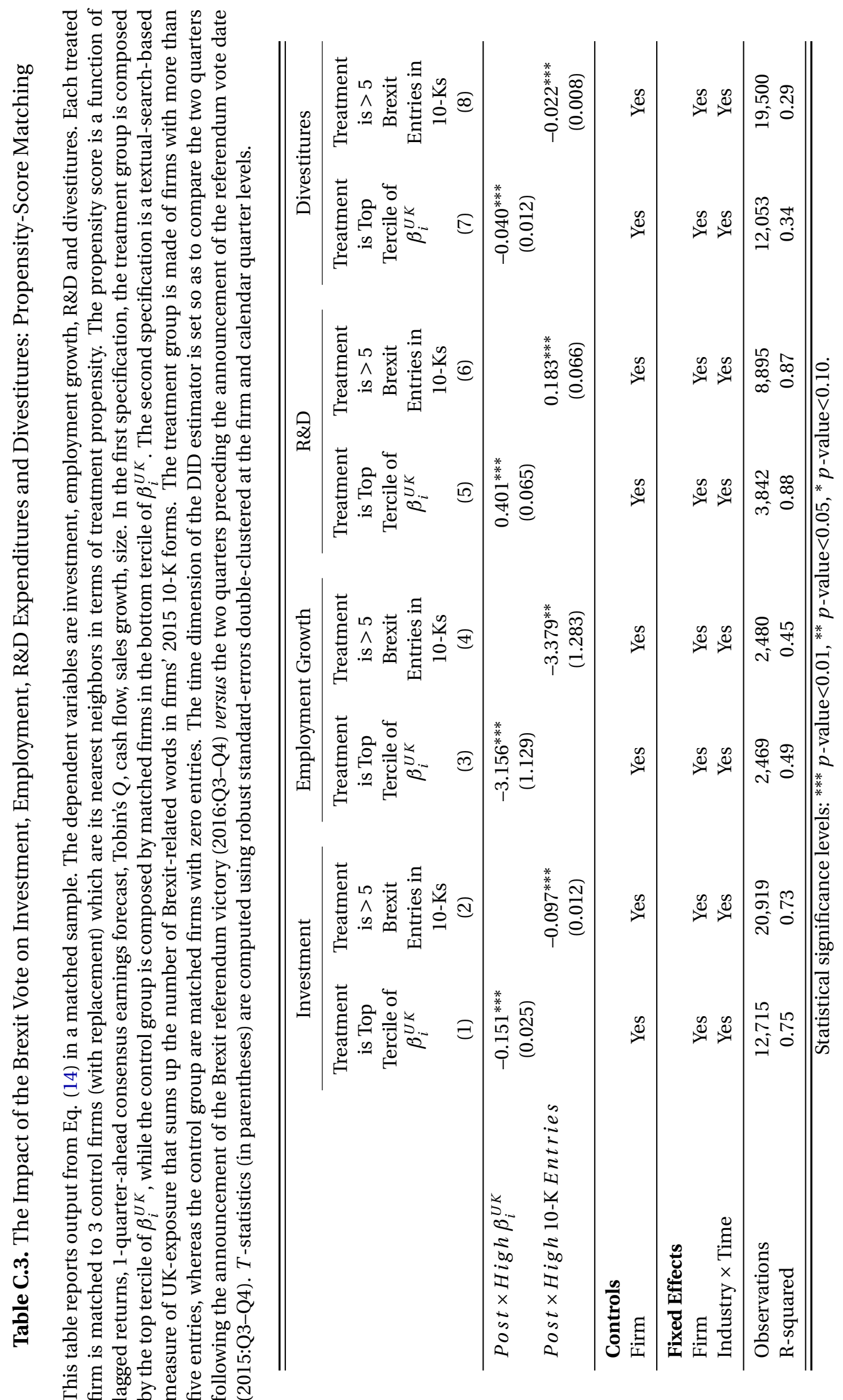


Table C.4. Parallel Trends: Market-Based Approach

This table reports the average investment (Panel A), employment growth (Panel B), R\&D (Panel C), and divestitures (Panel D) for firms in the treated and control groups going back different periods prior to Brexit. The treatment group is composed by the top tercile of $\beta_{i}^{U K}$, while the control group is composed by firms in the bottom tercile of $\beta_{i}^{U K}$. The table also reports the differences in means and the $p$-value associated with a test statistic for the differences.

\begin{tabular}{|c|c|c|c|c|}
\hline Periods prior to Brexit & Treated & Control & Difference & $p$-value \\
\hline & \multicolumn{4}{|c|}{ Panel A (Quarterly Frequency): Investment } \\
\hline One & 1.165 & 1.027 & 0.138 & 0.156 \\
\hline Two & 1.184 & 0.942 & 0.242 & 0.153 \\
\hline Three & 1.362 & 1.135 & 0.227 & 0.281 \\
\hline Four & 1.100 & 1.381 & -0.281 & 0.600 \\
\hline Five & 1.433 & 1.115 & 0.318 & 0.369 \\
\hline \multirow[t]{2}{*}{ Six } & 0.996 & 1.526 & -0.530 & 0.380 \\
\hline & \multicolumn{4}{|c|}{ Panel B (Annual Frequency): Employment Growth } \\
\hline One & 3.794 & 3.906 & -0.112 & 0.951 \\
\hline Two & 9.723 & 4.812 & 4.911 & 0.369 \\
\hline Three & 6.434 & 5.033 & 1.401 & 0.374 \\
\hline Four & 9.265 & 5.217 & 4.048 & 0.126 \\
\hline Five & 10.178 & 8.083 & 2.095 & 0.223 \\
\hline \multirow[t]{2}{*}{ Six } & 8.113 & 8.985 & -0.872 & 0.670 \\
\hline & \multicolumn{4}{|c|}{ Panel C (Quarterly Frequency): R\&D } \\
\hline One & 4.441 & 2.641 & 1.800 & 0.317 \\
\hline Two & 2.568 & 4.369 & -1.801 & 0.311 \\
\hline Three & 2.275 & 3.760 & -1.485 & 0.434 \\
\hline Four & 4.150 & 2.376 & 1.774 & 0.197 \\
\hline Five & 4.342 & 2.399 & 1.943 & 0.221 \\
\hline \multirow[t]{2}{*}{ Six } & 4.287 & 2.465 & 1.822 & 0.229 \\
\hline & \multicolumn{4}{|c|}{ Panel D (Quarterly Frequency): Divestitures } \\
\hline One & 0.076 & 0.057 & 0.019 & 0.234 \\
\hline Two & 0.056 & 0.102 & -0.046 & 0.748 \\
\hline Three & 0.071 & 0.077 & -0.006 & 0.710 \\
\hline Four & 0.073 & 0.054 & 0.019 & 0.218 \\
\hline Five & 0.071 & 0.054 & 0.017 & 0.289 \\
\hline Six & 0.056 & 0.043 & 0.013 & 0.304 \\
\hline
\end{tabular}


Table C.5. Parallel Trends: Textual-Search-Based Approach

This table reports the average investment (Panel A), employment growth (Panel B), R\&D (Panel C), and divestitures (Panel D) for firms in the treated and control groups going back different periods prior to Brexit. The treatment indicator is a textual-search-based measure of UK-exposure that sums up the number of Brexit-related words in firms' 2015 10-K forms. The treatment group is made of firms with more than five entries, whereas the control group are firms with zero entries. The table also reports the differences in means and the $p$-value associated with a test statistic for the differences.

\begin{tabular}{ccccc}
\hline \hline Periods prior to Brexit & Treated & Control & Difference & $p$-value \\
\hline & \multicolumn{5}{c}{ Panel A (Quarterly Frequency): Investment } \\
\cline { 2 - 5 } One & 0.958 & 1.064 & -0.106 & 0.202 \\
Two & 0.930 & 1.047 & -0.117 & 0.186 \\
Three & 1.124 & 1.203 & -0.079 & 0.419 \\
Four & 1.174 & 1.090 & 0.084 & 0.348 \\
Five & 1.194 & 1.140 & 0.054 & 0.570 \\
Six & 1.110 & 1.122 & -0.012 & 0.897 \\
& \multicolumn{5}{c}{} \\
One & Panel B (Annual Frequency): Employment Growth \\
\cline { 2 - 5 } Two & 9.711 & 8.881 & 0.830 & 0.678 \\
Three & 11.400 & 13.321 & -1.921 & 0.343 \\
Four & 7.600 & 6.290 & 1.310 & 0.448 \\
Five & 8.972 & 6.828 & 2.144 & 0.258 \\
Six & 10.286 & 10.076 & 0.210 & 0.914 \\
& 9.928 & 8.619 & 1.309 & 0.498 \\
& \multicolumn{5}{c}{ Panel C (Quarterly Frequency): R\&D } \\
One & 4.972 & 5.334 & -0.362 & 0.488 \\
Two & 4.830 & 5.054 & -0.224 & 0.653 \\
Three & 4.230 & 4.218 & 0.012 & 0.979 \\
Four & 4.246 & 4.423 & -0.177 & 0.683 \\
Five & 4.733 & 4.258 & 0.475 & 0.279 \\
Six & 4.263 & 4.419 & -0.156 & 0.729 \\
& \multicolumn{5}{c}{ Panel D (Quarterly Frequency): Divestitures } \\
\cline { 2 - 5 } One & 0.051 & 0.059 & -0.008 & 0.566 \\
Two & 0.062 & 0.058 & 0.004 & 0.783 \\
Three & 0.062 & 0.076 & -0.014 & 0.297 \\
Four & 0.066 & 0.054 & 0.012 & 0.378 \\
Five & 0.055 & 0.038 & 0.017 & 0.165 \\
Six & 0.039 & 0.046 & -0.007 & 0.578 \\
\hline \hline
\end{tabular}




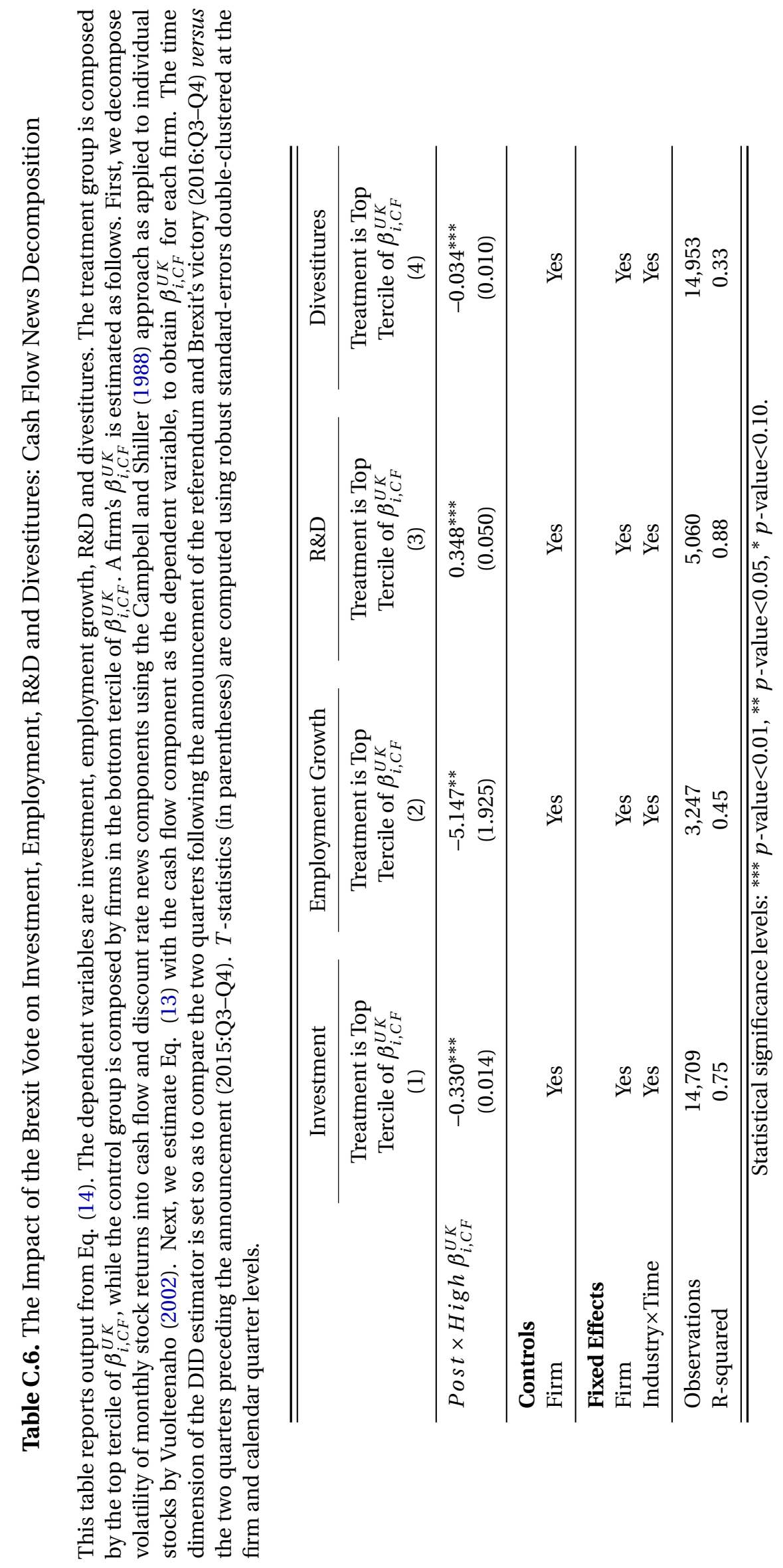


Table C.7. The Impact of the Brexit Vote on US Investment: First-Moment Controls

This table reports output from Eq. (14). The dependent variables are investment and employment growth. Investment is defined as capital expenditures divided by lagged total assets (quarterly). Employment growth is the percentage change in the number of employees (annual). In the first specification, the measure of UK-exposure $\left(\beta_{i}^{U K}\right)$ enters the regression as a linear continuous variable. In the second specification, the treatment group is composed by the top tercile of $\beta_{i}^{U K}$, while the control group is composed by firms in the bottom tercile of $\beta_{i}^{U K}$. The third specification is a textual-search-based measure of UK-exposure that sums up the number of Brexit-related words in firms' $201510-\mathrm{K}$ forms. The treatment group is made of firms with more than five entries, whereas the control group are firms with zero entries. The time dimension of the DID estimator is set so as to compare the two quarters following the announcement of the Brexit referendum victory (2016:Q3-Q4) versus the two quarters preceding the announcement of the vote date (2015:Q3-Q4). The specifications also include the first-moment instruments for the USD-GBP exchange rate, the price of oil, and the Treasury rate from Alfaro et al. (2018). $T$-statistics (in parentheses) are computed using robust standard-errors double-clustered at the firm and calendar quarter levels.

\begin{tabular}{|c|c|c|c|}
\hline & \multicolumn{3}{|c|}{ Panel A: Investment } \\
\hline & $\begin{array}{l}\text { Linear } \\
\text { Model }\end{array}$ & $\begin{array}{c}\text { Treatment } \\
\text { is Top } \\
\text { Tercile of } \\
\beta_{i}^{U K} \\
\\
\text { (2) }\end{array}$ & $\begin{array}{c}\text { Treatment } \\
\text { is }>5 \\
\text { Brexit } \\
\text { Entries in } \\
\text { 10-Ks } \\
\text { (3) }\end{array}$ \\
\hline Post & $\begin{array}{l}-0.042 \\
(0.030)\end{array}$ & & \\
\hline Post $\times \beta_{i}^{U K}$ & $\begin{array}{c}-0.127^{* * *} \\
(0.016)\end{array}$ & & \\
\hline Post $\times \operatorname{High} \beta_{i}^{U K}$ & & $\begin{array}{c}-0.182^{* * *} \\
(0.018)\end{array}$ & \\
\hline Post $\times$ High 10-K Entries & & & $\begin{array}{c}-0.063^{* * *} \\
(0.010)\end{array}$ \\
\hline Size & $\begin{array}{l}0.105^{* *} \\
(0.050)\end{array}$ & $\begin{array}{c}0.088 \\
(0.108)\end{array}$ & $\begin{array}{l}0.186^{* *} \\
(0.081)\end{array}$ \\
\hline Tobin's $Q$ & $\begin{array}{c}0.162^{* * *} \\
(0.018)\end{array}$ & $\begin{array}{c}0.108^{* * *} \\
(0.038)\end{array}$ & $\begin{array}{c}0.168^{* * *} \\
(0.021)\end{array}$ \\
\hline Cash Flow & $\begin{array}{c}1.486^{* * *} \\
(0.475)\end{array}$ & $\begin{array}{l}1.540^{*} \\
(0.760)\end{array}$ & $\begin{array}{c}0.270 \\
(0.542)\end{array}$ \\
\hline Sales Growth & $\begin{array}{l}0.059^{* *} \\
(0.028)\end{array}$ & $\begin{array}{c}0.056 \\
(0.046)\end{array}$ & $\begin{array}{c}0.032 \\
(0.025)\end{array}$ \\
\hline Consensus Earnings Forecast & $\begin{array}{c}0.051^{* * *} \\
(0.012)\end{array}$ & $\begin{array}{c}0.025 \\
(0.014)\end{array}$ & $\begin{array}{l}0.028^{* *} \\
(0.012)\end{array}$ \\
\hline Stock Returns & $\begin{array}{l}-0.053 \\
(0.044)\end{array}$ & $\begin{array}{c}0.117 \\
(0.083)\end{array}$ & $\begin{array}{l}-0.062 \\
(0.048)\end{array}$ \\
\hline Controls & & & \\
\hline $\begin{array}{l}\text { Macroeconomic } \\
\text { First-Moment Instruments }\end{array}$ & $\begin{array}{l}\text { Yes } \\
\text { Yes }\end{array}$ & $\begin{array}{l}\text { No } \\
\text { Yes }\end{array}$ & $\begin{array}{l}\text { No } \\
\text { Yes }\end{array}$ \\
\hline $\begin{array}{l}\text { Fixed Effects } \\
\text { Firm } \\
\text { Industry } \times \text { Time }\end{array}$ & $\begin{array}{l}\text { Yes } \\
\text { No }\end{array}$ & $\begin{array}{l}\text { Yes } \\
\text { Yes }\end{array}$ & $\begin{array}{l}\text { Yes } \\
\text { Yes }\end{array}$ \\
\hline $\begin{array}{l}\text { Observations } \\
\text { R-squared }\end{array}$ & $\begin{array}{c}41,630 \\
0.68\end{array}$ & $\begin{array}{c}17,199 \\
0.75\end{array}$ & $\begin{array}{c}21,253 \\
0.73\end{array}$ \\
\hline
\end{tabular}

Statistical significance levels: ${ }^{* * *} p$-value $<0.01,{ }^{* *} p$-value $<0.05,{ }^{*} p$-value $<0.10$. 


\begin{tabular}{|c|c|c|c|}
\hline & \multicolumn{3}{|c|}{ Panel B: Employment Growth } \\
\hline & $\begin{array}{l}\text { Linear } \\
\text { Model }\end{array}$ & $\begin{array}{c}\text { Treatment } \\
\text { is Top } \\
\text { Tercile of } \\
\beta_{i}^{U K} \\
\text { (2) }\end{array}$ & $\begin{array}{l}\text { Treatment } \\
\text { is }>5 \\
\text { Brexit } \\
\text { Entries in } \\
10-\text { Ks } \\
\text { (3) }\end{array}$ \\
\hline Post & $\begin{array}{c}1.986 \\
(2.787)\end{array}$ & & \\
\hline Post $\times \beta_{i}^{U K}$ & $\begin{array}{c}-3.999 * \\
(2.186)\end{array}$ & & \\
\hline Post $\times \operatorname{High} \beta_{i}^{U K}$ & & $\begin{array}{c}-4.924^{* * *} \\
(1.566)\end{array}$ & \\
\hline Post $\times$ High $10-K$ Entries & & & $\begin{array}{c}-1.111^{* *} \\
(0.545)\end{array}$ \\
\hline Size & $\begin{array}{c}16.997^{* * *} \\
(2.119)\end{array}$ & $\begin{array}{l}17.486^{* * *} \\
(2.590)\end{array}$ & $\begin{array}{c}16.156^{* * *} \\
(3.178)\end{array}$ \\
\hline Tobin's Q & $\begin{array}{c}3.288^{* * *} \\
(0.614)\end{array}$ & $\begin{array}{c}2.112 \\
(1.120)\end{array}$ & $\begin{array}{c}3.616^{* * *} \\
(0.898)\end{array}$ \\
\hline Cash Flow & $\begin{array}{l}-4.682 \\
(5.017)\end{array}$ & $\begin{array}{c}-10.845 \\
(6.515)\end{array}$ & $\begin{array}{l}-3.512 \\
(7.697)\end{array}$ \\
\hline Sales Growth & $\begin{array}{l}-1.738 \\
(1.058)\end{array}$ & $\begin{array}{l}-1.468 \\
(1.381)\end{array}$ & $\begin{array}{l}-0.734 \\
(1.620)\end{array}$ \\
\hline Consensus Earnings Forecast & $\begin{array}{l}0.288^{* *} \\
(0.101)\end{array}$ & $\begin{array}{l}-0.056 \\
(0.216)\end{array}$ & $\begin{array}{l}0.420^{* *} \\
(0.160)\end{array}$ \\
\hline Stock Returns & $\begin{array}{l}4.726^{* * *} \\
(0.969)\end{array}$ & $\begin{array}{c}5.563^{* * *} \\
(1.093)\end{array}$ & $\begin{array}{l}4.697^{* *} \\
(1.432)\end{array}$ \\
\hline Controls & & & \\
\hline $\begin{array}{l}\text { Macroeconomic } \\
\text { First-Moment Instruments }\end{array}$ & $\begin{array}{l}\text { Yes } \\
\text { Yes }\end{array}$ & $\begin{array}{l}\text { No } \\
\text { Yes }\end{array}$ & $\begin{array}{l}\text { No } \\
\text { Yes }\end{array}$ \\
\hline Fixed Effects & & & \\
\hline $\begin{array}{l}\text { Firm } \\
\text { Industry } \times \text { Time }\end{array}$ & $\begin{array}{l}\text { Yes } \\
\text { No }\end{array}$ & $\begin{array}{l}\text { Yes } \\
\text { Yes }\end{array}$ & $\begin{array}{l}\text { Yes } \\
\text { Yes }\end{array}$ \\
\hline $\begin{array}{l}\text { Observations } \\
\text { R-squared }\end{array}$ & $\begin{array}{c}9,143 \\
0.35\end{array}$ & $\begin{array}{c}3,540 \\
0.45\end{array}$ & $\begin{array}{c}4,173 \\
0.45\end{array}$ \\
\hline
\end{tabular}

Statistical significance levels: ${ }^{* * *} p$-value $<0.01,{ }^{* *} p$-value $<0.05,{ }^{*} p$-value $<0.10$. 


\section{Appendix D Timeline of Brexit Key Events}

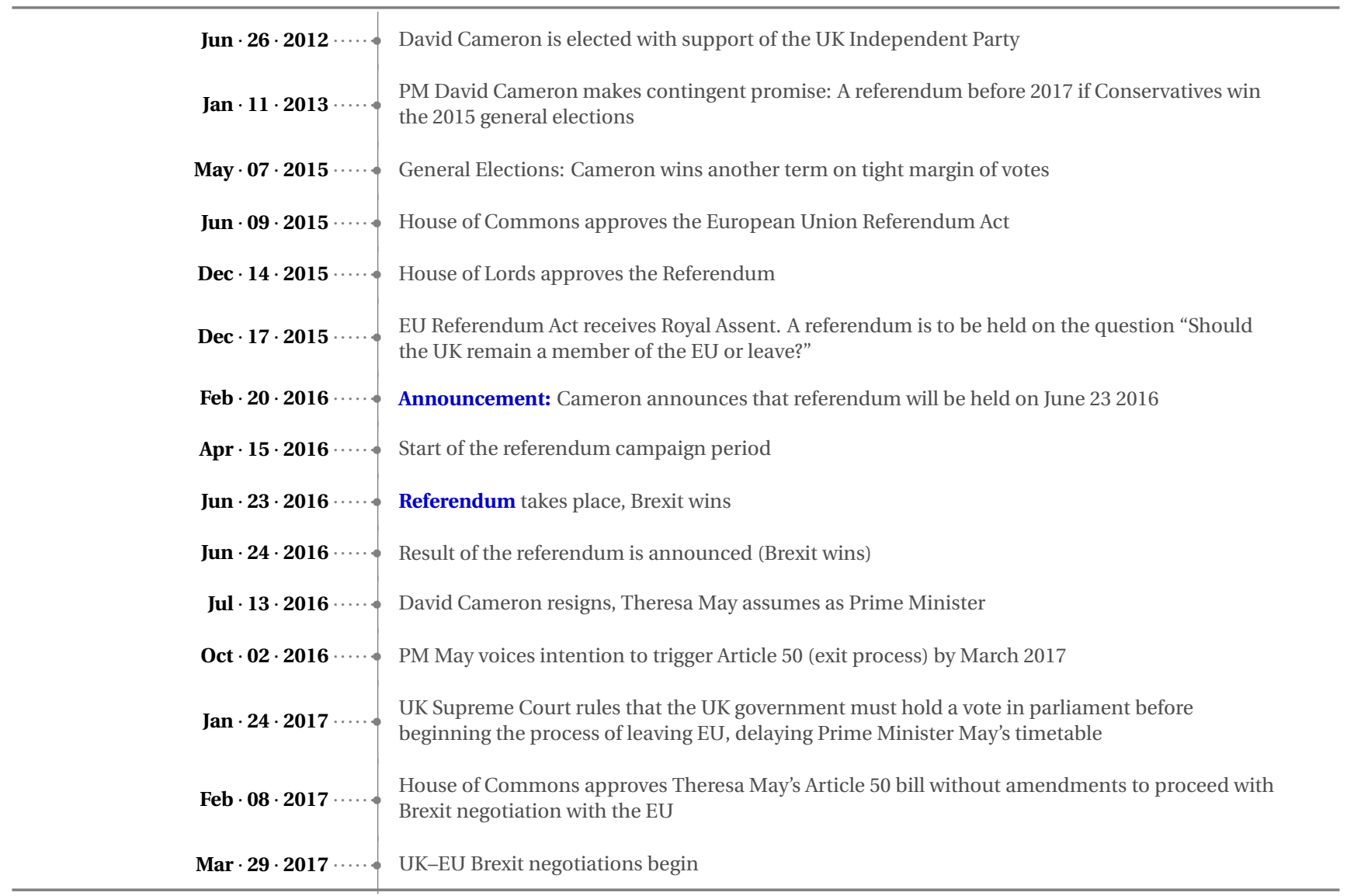

Figure D.1. Timeline of the Brexit Referendum. This figure lists the key events preceding the referendum leading to Brexit. Events in bold blue represent two key dates used in our analysis; the Announcement of the date when the referendum would be held, and the Referendum vote itself. 


\section{Appendix E Measures of Exposure to Automation}

\section{E.1 Details on Automation Exposure Measures}

For more details on the geographic measure of exposure to automation for all commuting zones in the continental US, we refer the reader to Acemoglu and Restrepo (2020) and Leigh and Kraft (2018). In this appendix, we describe in more detail the procedure to construct our text-based measure of automation exposure at the firm level. We draw inspiration from an extensive literature in corporate finance that uses textual analysis (e.g., Loughran and McDonald (2011)) and define a dictionary of keywords that capture automation at the firm level. We first gather the syllabuses of many courses on "Industrial Automation and Integration" taught at top Engineering schools in North America (MIT, CalTech, University of Toronto, among others). Reading each syllabus, we identify the most frequently adopted textbook. This analysis points to Benhabib's (2003) "Manufacturing: Design, Production, Automation, and Integration" as one of the most commonly required textbooks in these universities.

With the textbook in hand, we parse its full textual content and use a standard keyword ranking algorithm (“TextRank", see Mihalcea and Tarau (2004)) to order the most distinctive keywords reflecting automation. Following the usual procedures in textual analysis (e.g., exclusion of "stop words"), we select the top 100 keywords that are closely related to automation and use them as a dictionary for parsing firms' 10-Ks. Finally, we define Automation $_{i}$, which is a continuous variable (in logs) that measures how frequently the top 100 automation keywords appear in the firm's business description (Section 1 of the 10-K form) and management discussion (Section 7 of the $10-\mathrm{K}$ form). To capture cases in which a firm discusses automation efforts in only one year, we average the word count across all years in our sample. Automation ${ }_{i}=\log \left(1+\right.$ Automation $^{2}$ Keywords $_{i}$ ), where Automation Keywords $s_{i}$ is the number of mentions of the top 100 automation-related key-

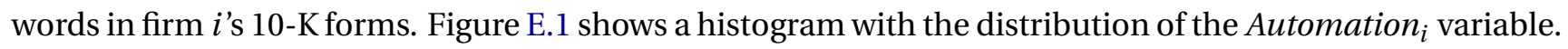




\section{E.2 Distribution of the Firm-Level Measure of Exposure to Automation}

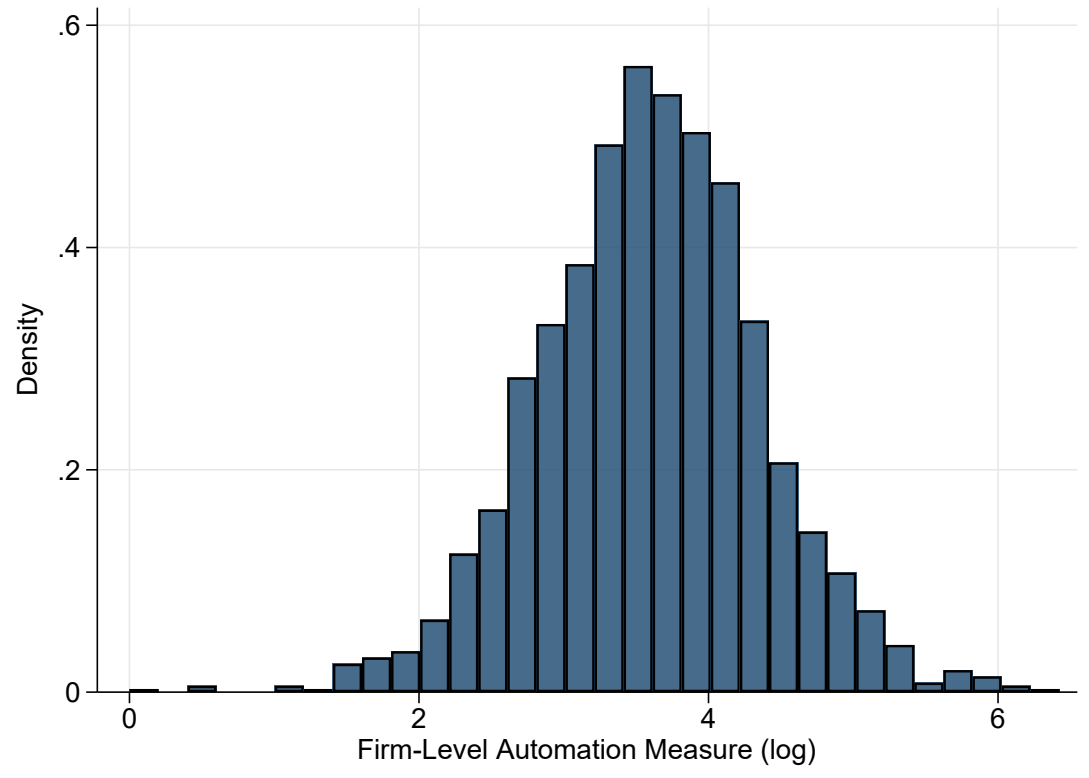

Figure E.1. Distribution of Firm-Level Measure of Automation Exposure. This figure shows the histogram of the text-based, firm-level measure of automation exposure. Specifically, the measure is constructed as Automation $_{i}=\log \left(1+\right.$ Automation Keywords $\left._{i}\right)$, where Automation Keywords $s_{i}$ is the number of mentions of the top 100 automation-related keywords in firm $i$ 's $10-\mathrm{K}$ forms as described in Subsection E.1. The total number of firm $i$ 's keyword mentions per year are then averaged across the pre-Brexit sample period of our baseline analysis (2010-15). 